\title{
La comisión científica del Pacífico: de la ciencia imperial a la ciencia federativa
}

La comision cientifica del pacifico: de la science imperiale a la science federative

The Comisión Científica del Pacífico: From Imperial Science to Federative Science

Leoncio López-Ocón

\section{OpenEdition Journals}

\section{Edición electrónica}

URL: http://journals.openedition.org/bifea/6118

DOI: 10.4000/bifea.6118

ISSN: 2076-5827

Editor

Institut Français d'Études Andines

Edición impresa

Fecha de publicación: 1 diciembre 2003

Paginación: 479-515

ISSN: 0303-7495

Referencia electrónica

Leoncio López-Ocón, « La comisión científica del Pacífico: de la ciencia imperial a la ciencia federativa », Bulletin de l'Institut français d'études andines [En línea], 32 (3) | 2003, Publicado el 08 diciembre 2003, consultado el 01 diciembre 2020. URL : http://journals.openedition.org/bifea/6118 DOI : https://doi.org/10.4000/bifea.6118

\section{c) (†)}

Les contenus du Bulletin de l'Institut français d'études andines sont mis à disposition selon les termes de la licence Creative Commons Attribution - Pas d'Utilisation Commerciale - Pas de Modification 4.0 International. 


\title{
LA COMISIÓN CIENTÍFICA DEL PACÍFICO: DE LA CIENCIA IMPERIAL A LA CIENCIA FEDERATIVA*
}

\author{
Leoncio LÓPEZ-OCÓN**
}

\section{Resumen}

En este artículo se analizan las redes de comunicación desplegadas por los integrantes de una expedición de naturalistas españoles que recorrieron gran parte de la América del Sur, América Central y California entre 1862 y 1865 , acompañados en la primera parte de su viaje por la cámara del fotógrafo Rafael Castro y Ordóñez. Con este análisis se intenta cumplir un triple objetivo. En primer lugar se muestra que esa expedición es la principal empresa de la ciencia imperial o neo-colonial que se intentó organizar en el reinado de Isabel II, vinculada a un programa de aclimatación promovido por la Societé Impériale Zoologique d'Acclimatation y desarrollada en el marco de un movimiento político-cultural panhispanista. En segundo lugar se pretende destacar el papel de los portavoces en el despliegue de las redes que, discontinuamente, han permitido el estudio de las colecciones científicas, iconográficas y documentales generadas por la Comisión Científica del Pacífico y construir en la actualidad el portal de Internet www.pacifico.csic.es. Y finalmente se subraya cómo, tras su experiencia de viajero naturalista, Marcos Jiménez de la Espada, el más destacado integrante de esa expedición científica, reorientó su mirada hacia el pasado para estudiar las antigüedades peruanas, y explorar las relaciones culturales y científicas habidas entre España y sus antiguas colonias americanas. Esos estudios "americanistas" sentaron las bases de una ciencia "federativa" iberoamericana, pues sus aportaciones historiográficas fueron hechas suyas por diversos lectores y científicos latinoamericanos, como los fundadores de la Sociedad Geográfica de Lima.

Palabras claves: Expediciones científicas, redes científicas, Marcos Jiménez de la Espada, Rafael Castro y Ordóñez, panhispanismo, americanismo científico, Société Impériale Zoologique d'Acclimatation, fotografías americanas.

\section{LA COMISIÓN CIENTÍFICA DEL PACÍFICO: DE LA SCIENCE IMPÉRIALE À LA SCIENCE FÉDÉRATIVE}

\section{Résumé}

Dans cet article on analyse les réseaux de communication déployés par une expédition de naturalistes espagnols qui ont parcouru une grande partie de l'Amérique du Sud, l'Amérique

\footnotetext{
* Este trabajo se inscribe en el marco de los proyectos TIC 2000-0168-P4-04 y BS020012341, financiados por el Ministerio de Ciencia y Tecnología de España.

**E-mail: lopez-ocon@ih.csic.es
} 
Centrale et la Californie entre 1862 et 1865 . Au cours de la première partie de son voyage, cette expédition fût accompagnée par l'appareil photographique de Rafael Castro et Ordóñez. A travers cette analyse nous voulons d'aboutir à un triple objectif. Montrer que cette expédition a été la principale entreprise de la science impériale ou néo-coloniale organisée sous le règne d'Isabel II, liée au programme d'acclimatation promu par la Société Impériale Zoologique d'acclimatation et développée dans le cadre d'un mouvement politique culturel panhispaniste. Mettre en relief le rôle des porte-paroles dans le déploiement des réseaux qui, d'une manière discontinue, ont contribué à l'étude des collections scientifiques, iconographiques et documentaires produites par la Comisión Científica del Pacífico, et construire aujourd'hui le site d'Internet www.pacifico.csic.es. Enfin souligner comment, après son expérience de voyageur naturaliste, Marcos Jiménez de la Espada, le plus important membre de cette expédition scientifique, a réorienté son regard vers le passé pour étudier les antiquités péruviennes, et explorer les relations culturelles et scientifiques entre l'Espagne et ses anciennes colonies. Ses études "américanistes" ont jeté les bases d'une science "fédérative" iberoaméricaine, car ses contributions historiographiques ont été appropriées par divers lecteurs et scientifiques latino-américains, comme les fondateurs de la Société Géographique de Lima.

Mots clés Expéditions scientifiques, réseaux scientifiques, Marcos Jiménez de la Espada, Rafael Castro y Ordóñez, panhispanisme, américanisme scientifique, Société Impériale Zoologique d'Acclimatation, photographies américaines.

\title{
THE COMISIÓN CIENTÍFICA DEL PACÍFICO: FROM IMPERIAL SCIENCE TO FEDERATIVE SCIENCE
}

\begin{abstract}
This work analyzes the communication networks that were unfolded by the members of an expedition of Spanish scientists that travelled over large areas of South America, Central America and California between 1862 and 1865. During the first half of this journey, the scientists were accompanied by the photographer Rafael Castro y Ordóñez. This analysis pursues three goals. First, to show that the aim of this expedition was the imperial or neo-colonial venture that was organized during the reign of Isabel II. It was connected to an acclimatization programme promoted by the Société Impériale Zoologique d'Acclimatation and carried out within the framework of a pan-hispanist political and cultural movement. Secondly, to underline the fundamental contribution of the spokesmen who were active in the aforementioned networks that were unfolded by the members of this scientific expedition. These networks have allowed, in a discontinuous way, to study the scientific, iconographic and documentary collections that the Comisión Científica del Pacífico generated. They have also allowed, nowadays, to create the website www.pacifico.csic.es . Finally, to underline the fact that Marcos Jiménez de la Espada, the most outstanding member of this scientific expedition, after his travel started his studies on the Peruvian antiquities, as well as on the cultural and scientific relations that Spain and its former colonies maintaned in America. These "American Studies" laid the foundations of an iberoamerican "federative science" because his contribution to Historiography was taken as fundamental by many Latin-American readers and scientists -for instance, the foundation members of the Sociedad Geográfica de Lima.
\end{abstract}

Key words: Scientific Expeditions, Scientific Networks, Marcos Jiménez de la Espada, Rafael Castro y Ordónez, Pan-hispanism, Scientific Americanism, Société Impériale Zoologique d'Acclimatation, American Photographs. 


\section{INTRODUCCIÓN}

En un reciente trabajo la investigadora Emma Spary ha enfatizado el doble trabajo al que se ven sometidas "las muestras del mundo natural", de las que depende la práctica de la historia natural. Por una parte son desplazadas desde tierras lejanas a las instituciones productoras de esa historia natural. Pero también durante su recorrido han de ser preservadas para convertirlas en móviles inmutables, es decir en el tipo de inscripciones que según Bruno Latour permiten al científico salir y volver de su laboratorio con "algo" (Latour, 1986). La historia natural es contemplada de esta manera como una ciencia-red, en tanto que su proceso de producción de conocimientos, o de elaboración de inscripciones, está construido sobre redes de comunicación (Spary, 2000: 97). Es el despliegue de esas múltiples redes el que permite obtener muestras de la naturaleza, reunirlas en colecciones, transformarlas en inscripciones en los laboratorios y diseminarlas en la sociedad.

Tras este planteamiento analítico de contemplar a la historia natural como una ciencia de redes, subyace la teoría del actor-red desarrollada por diversos sociólogos de la ciencia, particularmente por Latour (Latour, 1992; Latour \& Polanco, 1990; Law \& Hassard, 1999) (1), con la que se ha intentado esclarecer de qué manera las inscripciones que van y vienen de los laboratorios se inician, se controlan y se dirigen hacia la sociedad. Tales inscripciones y las interpretaciones que se hacen sobre ellas se van construyendo y adquiriendo progresivamente. En el mantenimiento de las redes de comunicación que alimentaron el cultivo de la historia juegan un papel fundamental los portavoces, como ha subrayado Michel Callon (2). En efecto las redes se hacen presentes en los laboratorios porque los portavoces circulan del exterior hacia el interior, pero a su vez el laboratorio se hace presente en las redes gracias a que los portavoces van también del interior hacia el exterior. El laboratorio, constituye, ciertamente, un pequeño microcosmos pero puede movilizar todo un macrocosmos e intervenir sobre él, si logra reunir un número importante de portavoces y formar una cadena de representantes larga, segura y fiable. Se forma entonces una especie de "ciencia procesionaria", según la ha denominado Callon, ya que los portavoces confluyen y salen de los laboratorios en una procesión continua (Callon, 1988, cap. 2: fig. 2). De esta manera tras la actividad de los cultivadores de la historia natural, o de cualquier otra disciplina científica, hay que ver no sólo los recursos concentrados en el laboratorio, sino también las redes que se están movilizando continuamente por medio de un puñado de portavoces. Son estas redes, que se movilizan continuamente, las que proporcionan un espacio de circulación a los hechos científicos, que como sabemos se caracterizan por su capacidad de resistir a la crítica y su facultad de interesar a diversos actores sociales.

Partiendo de estas consideraciones metodológicas intentaré aproximarme a un caso de estudio: el de la Comisión Científica del Pacífico, una expedición de naturalistas

(1) Una bibliografía anotada sobre esta teoría se encuentra en: www.comp.lancs.ac.uk/ sociology/jlaw.html

(2) Estos portavoces, según los define Michel Callon, son aquellos representantes que al ser movilizados movilizan consigo a todos los actores humanos y no humanos que representan (Callon, 1988: 16). 
españoles que recorrió tierras americanas entre 1862 y 1865. Analizaré las redes desplegadas a lo largo del tiempo y el espacio por esa expedición, que puede ser considerada la principal empresa relacionada con la construcción de una ciencia imperial o neo-colonial en el reinado de Isabel II (3) siguiendo la siguiente estrategia. En primer lugar se dará cuenta de las idas y vueltas de esa empresa científica trasatlántica, fijándome fundamentalmente en la explicación de los siguientes hechos: por qué se tomó la decisión de desplazar un grupo de seis naturalistas y dos auxiliares a mundos extraeuropeos; cómo una movilización científica modesta tuvo una cierta originalidad al incorporar a ella una cámara fotográfica con la que se captaron imágenes que circularon por el espacio atlántico; y de qué manera esos comisionados, en medio de innumerables dificultades, lograron generar una importante colección científica.

Posteriormente se presentarán algunas de las peripecias de esas colecciones adoptando una perspectiva analítica de larga duración pues se seguirán algunas de las redes que se desplegaron en torno a ellas desde que se exhibieron por primera vez en el Jardín Botánico de Madrid en 1866. Con ese rastreo vamos a intentar demostrar que el estudio de las colecciones documentales, científicas e iconográficas generadas por la Comisión Científica del Pacífico tuvo un carácter discontinuo, lo que corroboraría una característica estructural de las actividades científicas españolas: su guadianización. Con este neologismo, alusivo a un río de la España interior que circula discontinuamente López Piñero ha querido subrayar los altibajos y discontinuidades de los esfuerzos hechos por los científicos españoles (4), que explicarían la posición semiperiférica ocupada por la ciencia española en la ciencia-mundo (Polanco, 1990; López-Ocón, 1995).

Finalmente haremos una reflexión acerca de cómo la tarea emprendida desde 1998 por un equipo pluridisciplinario del CSIC para construir un servidor de información world wide web sobre las colecciones documentales y científicas de la Comisión Científica del Pacífico (www.pacifico.csic.es) está permitiendo prolongar en el espacio y en el tiempo la circulación de las inscripciones generadas por esa empresa científica del siglo XIX, y está creando las condiciones para construir una actividad científica cooperativa y federativa entre investigadores españoles y latinoamericanos, como lo prueba, por ejemplo, la prevista edición en Santiago de Chile por el Centro de Estudios Diego Barros Arana, adscrito a la Biblioteca Nacional de ese país, de un libro en el que se recogen y analizan las imágenes chilenas de Rafael Castro y Ordóñez, el fotógrafodibujante de la Comisión Científica del Pacífico.

\section{IDAS Y VUELTAS DE UNA COMISIÓN CIENTÍFICA}

Debido al prestigio de Alejandro de Humboldt (López-Ocón, 1999) el continente americano fue uno de los espacios geográficos adonde se dirigieron con predilección

(3) Sorprende por ello que no se haga ninguna alusión a esa empresa científica en el último balance que se ha hecho de la proyección colonial de la ciencia en la España del siglo XIX por parte de Elena \& Ordóñez (2000).

(4) Esta idea está presente sobre todo en López Piñero (1979). Ver al respecto López-Ocón (2003: 9-20) 
los naturalistas europeos en las décadas centrales del Ochocientos. En el intervalo de pocos años se organizaron diversas empresas colectivas destinadas a la exploración y estudio de la naturaleza y las culturas de ese mundo, nuevo para una óptica europea. Entre esas expediciones científicas cabe destacar tres de ellas organizadas en Viena, Madrid y París.

Una de las últimas actividades llevadas a cabo por Alejandro de Humboldt (Beck, 1971) fue la de dar una serie de instrucciones y consejos a algunos de los expedicionarios del viaje de circunnavegación que la fragata Novara, del imperio austrohúngaro, emprendió en 1857 desde el puerto de Trieste y que culminó en 1859 (Treffer, 1973) (5), bajo el mando del comodoro B. von Wüllerstorf-Urbair. Pocos años después, en 1864, el Segundo imperio francés organizó desde París la Commission scientifique du Mexique, después de que se produjera la invasión de México por un ejército combinado de tres países europeos - Francia, el Reino Unido y España - que reclamaban el pago de deudas a sus connacionales, y tras la ulterior retirada de esa aventura imperialista de las tropas británicas, y españolas (López-Ocón, 1995; Soberanis, 1998).

En el período que medió entre esas dos aventuras se organizó en Madrid otra expedición europea a tierras de Ultramar cuando un hecho político se tradujo en un fenómeno científico. En la primavera de 1862, el gobierno español tomó una doble decisión. Resolvió enviar una escuadrilla naval formada por dos buques de la Armada a las aguas del Pacífico con el fin de dar la vuelta al mundo -como había hecho la fragata austro-húngara Novara- por la vía de la América del Sur y de las Filipinas. Luego determinó que se sumasen al viaje de las fragatas Triunfo y Resolución la Comisión Científica del Pacífico, nombre que recibió el grupo de seis naturalistas (tres zoólogos, un geólogo, un botánico y un antropólogo) (Fig. 1) y dos auxiliares (un taxidermista y un dibujante-fotógrafo) que se seleccionaron para hacer ese proyectado viaje de circunnavegación junto a los marinos de la flotilla de la Armada.

Política y ciencia se unieron en el Madrid de 1862 por la atmósfera panhispanista existente en las elites dirigentes en la última fase del reinado de Isabel II (Van Aken, 1959; López-Ocón, 1987: 60-88). Hubo por aquellos años una pequeña belle époque como resultado de los inicios del capitalismo español (Tortella, 1975) y se aspiró entonces a recuperar el rango de gran potencia en el escenario internacional (6). El inicio de la guerra de Secesión en Estados Unidos en 1861 facilitó una activa política en la América latina destinada a trazar una barrera al expansionismo norteamericano, tanto en la América media como en la cuenca del Pacífico. Como consecuencia de esos planes geoestratégicos se organizó el viaje de circunnavegación de las fragatas Triunfo y Resolución para establecer una estación naval española en el litoral del Pacífico sudamericano, similar a la que ya existía desde 1845 en Montevideo, con el fin de articular las diferentes y fragmentarias piezas del sistema colonial esparcido por América, Asia y Oceanía. De hecho parece ser que los comisionados recibieron órdenes de estudiar un emplazamiento favorable para instalar esa posible base naval en el litoral

(5) Información sobre esta expedición se puede obtener en la exposición virtual, "The Discovery of the World. The World of Discoveries". December 2001. Kunthistorisches Museum Wien. 30 julio 2003. http://www.khm.at/entdeckungen/frame_einE.html

(6) Una visión general de esa política exterior en Durán de la Rúa (1979). 


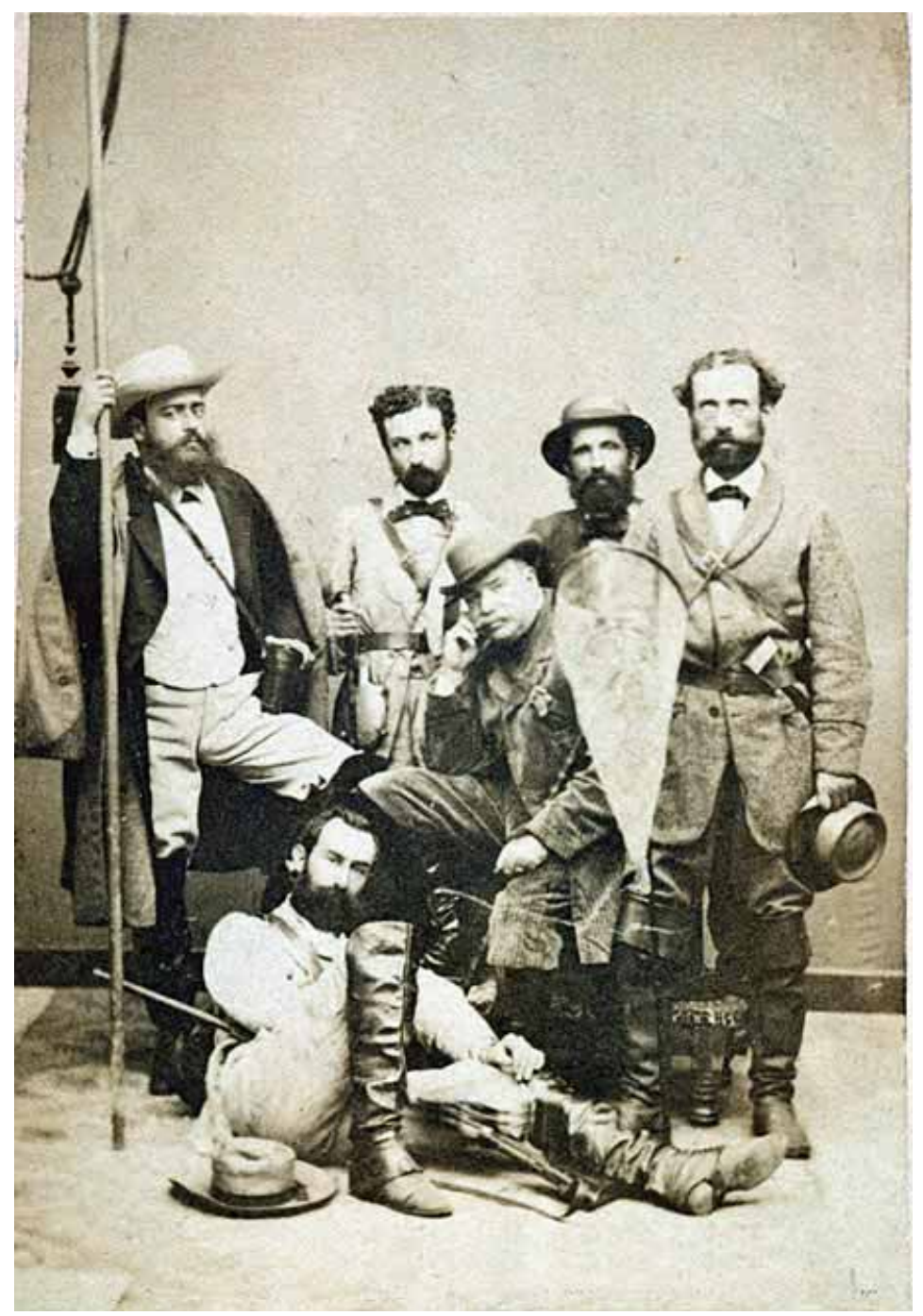

Fig. 1 - Retrato de los seis naturalistas de la Comisión Científica del Pacífico hecho por Rafael Castro y Ordóñez en Montevideo hacia diciembre de 1862. De pie, y de izquierda a derecha: el antropólogo Manuel Almagro, el zoólogo Francisco de Paula Martínez y Sáez, el botánico Juan Isern, y el entomólogo y geólogo Fernando Amor.

En el centro el presidente de la Comisión el conquiliólogo Patricio María Paz y Membiela. Sentado en el suelo, en primer plano, el zoólogo Marcos Jiménez de la Espada. ABGH000/112/259(7).

(7) Las siglas ABGH corresponden al Archivo de la Biblioteca General de Humanidades del CSIC. El autor agradece a los responsables de la custodia del fondo Marcos Jiménez de la Espada depositado en ese archivo su autorización para reproducir algunos de los documentos iconográficos que se conservan en él. 
americano del Pacífico (8), un área que se había revalorizado económica y estratégicamente a partir de los hallazgos auríferos de California y Australia de 1848.

Pero además existió la convicción de que el incipiente sistema científico-técnico, que se estaba reconstruyendo a duras penas tras la crisis de las primeras décadas del siglo XIX, podía ponerse al servicio de esa agresiva política exterior neocolonial, entre otras razones porque había científicos que tenían ya una experiencia acumulada en la dimensión colonialista de la ciencia. Así sucedía con algunos de los viajeros naturalistas seleccionados, o con el mismo proyecto científico subyacente en la organización de la expedición, muy vinculado al programa de trabajo de la Société Impériale Zoologique d'Acclimatation.

En efecto, tres de los viajeros naturalistas seleccionados tenían experiencia colonial: el presidente, Patricio $\mathrm{M}^{\mathrm{a}}$ Paz y Membiela (1808-1874), había sido oficial de la Armada y residido largo tiempo en Cuba, donde se aficionó al cultivo de las ciencias naturales en contacto con el naturalista Felipe Poey y con el conquiliólogo Nicolás Gutierrez (9); el encargado de los estudios antropológicos y etnográficos era el médico de origen cubano Manuel Almagro (1834-1895), y sobre todo Fernando Amor (18201863), vicepresidente de la expedición y encargado de los estudios geológicos y entomológicos. Amor, miembro de la Sociedad entomológica de Francia, era el naturalista más experimentado del grupo, y estaba muy vinculado a proyectos "utilitaristas" de la ciencia isabelina. En 1855 la Diputación de la provincia andaluza de Córdoba le nombró representante oficial en la Exposición Universal de París con el doble objetivo de dar a conocer los productos agrícolas de la campiña cordobesa y exponer a su retorno los adelantos de la agricultura europea que se pudiesen transferir al campo andaluz (Amor, 1856). Ese viaje de ida y vuelta de un científico provinciano al corazón de Europa hizo factible la creación en Córdoba de una Escuela Elemental de Agricultura, de la que Amor fue elegido director en 1858, y en la que se preocupó por dar una base científica y "racional" al estudio de la Agricultura creando una "granjamodelo" (Puig-Samper, 1988: 44-45). Muy poco después hizo un viaje de exploración al norte de Marruecos de tres semanas durante el verano de 1859 (Amor, 1859), donde - como apunta algún historiador (10) - es posible que formase parte de una comisión encargada de reconocer el terreno que poco después recorrería el ejército español cuando se desencadenó una guerra con el Imperio de Marruecos en 1860.

De una manera u otra los mencionados naturalistas formaban parte de un movimiento existente en la Europa de aquel tiempo por el que la ciencia estaba

(8) Así en la Memoria del viaje, publicada originariamente en 1866, y reeditada en 1984, dice su autor, el antropólogo de la Comisión, Manuel Almagro (1984: 77): "Guayaquil no está precisamente sobre el Pacífico, y sí sobre el río Guayaz (sic), que lo hace comunicar con el Océano; en la desembocadura del río está situada la isla de Puná, cuya topografía es ventajosísima para una estación marítima."

(9) Sobre el ambiente científico de La Habana a mediados del siglo XIX ver López-Ocón \& García-Montón (2000).

(10) ver F. Barras de Aragón, 1949 - Los últimos escritores de Indias. Bibliografía de españoles del siglo XIX que escribieron sobre países de fuera de Europa o viajaron por ellos: 26; Madrid, citado por Puig-Samper (1988: 45). 
estrechamente vinculada a la nueva expansión colonial protagonizada por una activa "burguesía conquistadora". Las grandes potencias coloniales impulsaron entonces vastos programas de investigación para proseguir los sueños dominadores del siglo XVIII: el de trasladar muestras de la naturaleza exótica a los laboratorios europeos para dominarla y domesticarla mediante el conocimiento (Mackenzie, 1990). La creación de la Société Zoologique d'Acclimatation en 1854 por Isidore Geoffroy Saint-Hilaire (1805-1861) - convertida en imperial al año siguiente al obtener el patrocinio de Napoleón III - es un caso elocuente del papel desempeñado por los científicos en la expansión colonial europea. Ahora bien, aunque como ha mostrado Michael Osborne la aclimatación - basada en la teoría de la variabilidad limitada del tipo (11) - fue concebida como una ciencia al servicio de la política colonial francesa, particularmente en Argelia (Osborne, 1994; 2000), no es menos cierto que desde que se puso en movimiento tuvo una clara dimensión internacionalista.

Pues bien, según ha mostrado recientemente Santiago Aragón (2002) hubo una significativa participación española en esa Sociedad cuando la dirigió Isidore Geoffroy Saint-Hilaire, entre 1854 y 1861, justo en vísperas de la organización de la Comisión Científica del Pacífico. Esta empresa científica puede ser vista entonces como un portavoz más de las redes desplegadas por la Société Impériale Zoologique d'Acclimatation, y como un elemento más de la ciencia procesionaria que puso en marcha Isidore Geoffroy Saint-Hilaire. En efecto, uno de los corresponsales más activos de la mencionada Sociedad fue Mariano de la Paz Graells (1809-1898), todopoderoso director del Museo de Ciencias Naturales de Madrid entre 1851 y 1867, elegido en 1855 uno de los tres primeros delegados de la Sociedad en el extranjero junto a otros colegas de Londres y Turín, y promotor de la Comisión Cientifica del Pacífico.

Graells, según se deduce de la correspondencia que intercambió con Isidore Geoffroy Saint-Hilaire y otros integrantes de la Société Impériale Zoologique d'Acclimatation, participó activamente en las tareas de la Sociedad. Si bien no era un naturalista de primera talla, sí estaba convencido - como tantos otros colegas de su época - de la utilidad social de su práctica científica, y creía que el cultivo de las ciencias debía contribuir a realzar el prestigio del estado nacional que se estaba construyendo durante el segundo tercio de ese siglo XIX. Científico nacionalista, como otros tantos de su grupo generacional (LópezOcón, 1992; 2000a), tuvo, en efecto, un empeño particular en restablecer una tradición científica y para ello reivindicó el papel de los españoles en la práctica de la aclimatación durante la era moderna (12). Sus argumentos consiguieron convencer a Isidore Geoffroy

(11) Así en la obra fundacional de la disciplina Acclimatation et domestication des animaux utiles (París, 1861: 58) Isidore Geoffroy Saint-Hilaire explica, basándose en su teoría de la variabilidad limitada del tipo que "Acclimater un animal, un végétal, c'est imprimer à son organisation des modifications qui le rendent propre à vivre et à perpétuer son espèce dans des conditions nouvelles d'existence". Citado por Aragón (2002: 81 nota 8). Una amplia discusión sobre los fundamentos científicos de la aclimatación en Francia en Osborne (1994: 62-97).

(12) Sur l'acclimatation des animaux en Espagne, lettre adressée à M. Isidore Geoffroy SaintHilaire, Président de la Société zoologique d'acclimatation, par M. le Docteur M.P. Graells, directeur du Muséum des Sciences Naturelles à Madrid, etc. Traduite de l'espagnol par M. le Docteur Alvaro Reynoso, membre de la Société, Bulletin de la Société impériale zoologique d'acclimatation, 1855. 
Saint-Hilaire, quien a su vez se convertiría en portavoz de las tesis de Graells (13)en el seno de la sociedad que dirigía.

El director del Museo de Madrid se mostró muy sensible al papel del mecenazgo de los poderosos. De hecho adquirió fama cuando en 1848 descubrió en los pinares de la sierra de Gredos la mariposa Graellsia isabellae, que dedicó a la reina Isabel II (Viejo Montesinos, 1992). Tiempo después —en 1857 - maniobró desde su posición de delegado de la Sociedad en Madrid para que se recompensase a la reina por los apoyos que la Casa Real había dado a la aclimatación, tanto en la metrópoli como en sus colonias americanas. Y en 1859 consiguió que se diese otra de las principales condecoraciones de la Sociedad al rey consorte por haber introducido en España un rebaño de llamas y alpacas del Perú (Aragón, 2002: 50-51). Ese carácter de científico cortesano hizo factible que Graells obtuviese el apoyo real para el establecimiento de un parque de domesticación y aclimatación de animales en el jardín botánico, cuya breve historia - pues se cerró en 1871 - está estrechamente relacionada con las vicisitudes de la Comisión Científica del Pacífico.

De hecho en las instrucciones que se dieron a los viajeros naturalistas (14), bastante improvisadas, pues según su redactor fueron escritas "del modo como las ideas se han ido agolpando a la memoria”, se insistió reiteradamente en la misión que debían cumplir esos agentes que se enviaban a tan larga distancia: recoger con cuidado y meticulosamente muestras y especímenes botánicos y zoológicos que contribuyesen a desarrollar la ciencia de la aclimatación que Graells tenía empeño en desarrollar.

Así uno de los objetivos del botánico de la expedición debía de ser:

"aprovechar cuantas ocasiones se presenten para remitir a España las semillas, así como tubérculos, bulbos y raíces de plantas vivas, y éstas convenientemente dispuestas para que lleguen en buen estado y puedan someterse a los oportunos ensayos para lograr un cultivo entre nosotros, entendiéndose que ha de darse preferencia a las plantas útiles, sin desechar las de adorno, ni las de interés puramente científico."

La vaguedad de esa petición contrasta con la mayor especificidad y detallismo de las instrucciones que se impartieron a los zoólogos. Se enumeraban, por ejemplo, los ejemplares de mamíferos que se deberían recolectar como especies útiles para la peletería, tales como el castor de Canadá, “animal que concluirá por extinguirse si la civilización no se apresura a domesticarle y multiplicarle". En cuanto a aves se insistía en que era prioritario que los viajeros obtuviesen y enviasen al nudo de la red -es decir al jardín zoológico de aclimatación del Jardín Botánico de Madrid - animales de lugares tan variados como el avestruz africano de Senegal, el ñandú de Buenos Aires o

Tome deuxième: 109-116. Un reciente balance de esa práctica de aclimatización respecto a las plantas en Fernández Pérez \& González Tascón, 1990.

(13) Ver por ejemplo Isidore Geoffroy Saint-Hilaire, Acclimatation et domestication des animaux utiles, Paris, La Maison Rustique (1861: 466-468), citado por Aragón (2002: 8). Más información sobre ese reconocimiento extraída de la correspondencia entre ambos naturalistas en Aragón, 2002: 55.

(14) Esas instrucciones se aprobaron el 7 de junio de 1862 por una comisión consultiva de académicos y de profesores de ciencias. Están reproducidas en Puig-Samper (1988: 421-435). 
el cisne negro de Nueva Holanda, recomendando además que se enviasen "vivos ejemplares del serpentario, o mensajero del Cabo de Buena Esperanza, ave de rapiña que se supone utilísima para destruir las culebras venenosas". Ese catálogo de recomendaciones finalizaba con la consideración de que si bien todas las clases del grupo de invertebrados eran interesantes, los viajeros tenían que hacer un esfuerzo especial para remitir "los huevos y capullos de los bombys seríferos, las cochinillas y sobre todo las abejas de miel de los diferentes países, enviando bien resguardadas las colmenas con sus larvas, para que transformándose en España puedan reproducirse los enjambres de reinas y zánganos", advirtiendo además que en Madagascar había unas abejas cuya miel era verde y que sería conveniente su introducción en Europa.

Para llevar a cabo ese programa de aclimatización, quimérico dado que a la mayor parte de esos lugares no se desplazaron los viajeros, se eligieron hombres de confianza de los dos promotores científicos de la expedición, no bien avenidos por cierto (15): el mencionado Graells y Laureano Pérez Arcas (1824-1894), su rival en el campo de la zoología española en aquella época (16).

De hecho fueron elegidos primer y segundo ayudantes naturalistas de la Comisión Francisco de Paula Martínez y Sáez (1835-1898) y Marcos Jiménez de la Espada (18311898), discípulos predilectos de Pérez Arcas y Graells, respectivamente. Martínez, elegido secretario de la Comisión, fue encargado de hacer las colecciones de mamíferos y reptiles acuáticos, peces, crustáceos, anélidos, moluscos y zoofitos, mientras que a Jiménez de la Espada se le responsabilizó de las colecciones de aves y mamíferos y reptiles terrestres. Ambos habían sido ayudantes de sus maestros en el Museo de Ciencias Naturales, y Jiménez de la Espada (Fig. 2) había sido el hombre de confianza de Graells en sus proyectos de aclimatización de animales útiles para la economía española, pues desde que se creó en 1859 el parque zoológico de aclimatización en el Jardín Botánico de Madrid era él el responsable del cuidado de los animales.

Los tres auxiliares - el dibujante-fotógrafo, y sobre todo el colector botánico y el taxidermista - también parecían estar en la órbita de Graells. Cuando se adscribió a la Comisión Juan Isern (1821-1866) era un laborioso botánico catalán. Sus conocimientos habían atraído la atención de varios sabios europeos como Willkomm, con quien intercambió plantas de Cataluña por las de Alemania. Desde que se instaló en Madrid en 1851 como colector del Jardín Botánico, recibió el apoyo constante de Graells. Por su parte el taxidermista elegido fue el médico catalán Puig y Galup (1826?), ayudante disecador y preparador del Gabinete de Historia Natural de la Universidad de Barcelona, ciudad con la que Graells mantenía una fuerte vinculación desde que entre 1835 y 1837 - antes de su ida a Madrid - , se hiciese cargo de la cátedra de Zoología y Taxidermia de la Academia de Ciencias Naturales de esa ciudad.

(15) Así se deduce de la carta que escribiera Marcos Jiménez de la Espada a Mariano de la Paz Graells en Cádiz el 30 de julio de 1862. Reproducida en Barreiro (1926: 501-508).

(16) Pérez Arcas fue autor de Elementos de zoología (1863, $2^{\text {a }}$ ed.), el primer tratado escrito en español para la enseñanza de la zoología, miembro de la Société impériale zoologique d'acclimatation desde 1860 y sucesor de Graells en la dirección del mencionado parque de aclimatación zoológica del jardín botánico cuando su rival cayó en desgracia a partir de 1867. 


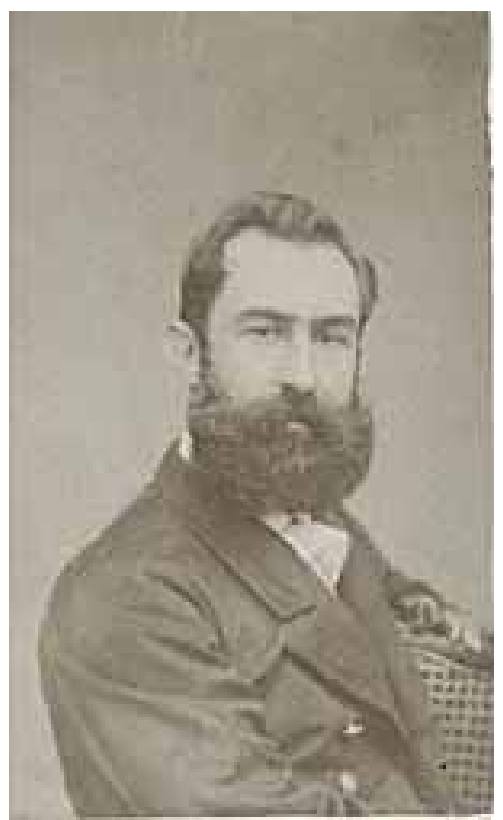

Fig. 2 - Carte de visite. Retrato de Marcos Jiménez de la Espada por Rafael Castro y Ordóñez hacia 1862 ó 1863. ABGH000/113/262.

El programa aclimatizador subyacente a la organización de la Comisión sería un indicador del afán de convertir al Museo de Ciencias Naturales en un nudo de la red de establecimientos científicos y laboratorios europeos que quería desplegar desde París Isidore Geoffroy de Saint-Hilaire a través de la Société Zoologique d'Acclimatation, para desarrollar la "ciencia de la aclimatación".

Pero disponemos de otro importante indicio de la apuesta que hicieron esos representantes de la elite científica isabelina por ser innovadores en sus prácticas de trabajo. Nos referimos a la decisión tomada en esa primavera de 1862 de añadir una cámara fotográfica al grupo expedicionario de la Comisión Científica del Pacífico.

En efecto, el octavo integrante del grupo expedicionario fue el artista Rafael Castro y Ordóñez, nombrado dibujante-fotógrafo de la comisión (Fig. 3). Desconocemos si este pintor poseía conocimientos sobre fotografía. Pero sí sabemos que recibió instrucciones, sobre todo para hacer vistas (Puig-Samper, 1988: 24), del fotógrafo más reputado de su época en España, el británico Charles Clifford (1819-1863), quien jugó un importante papel en el intento de construir una imagen "amable" del reinado de Isabel II con su labor propagandística de las grandes obras públicas construidas en Madrid durante la década de 1850 (Fontanella, 1999).

No ha de extrañar la introducción de ese elemento innovador en el seno de la expedición. Era notable la afición en Madrid por ese nuevo arte (17). Sabían además

(17) Ver al respecto, por ejemplo, "Noticias sobre la historia de la fotografía", por el conde de Benazuna (1859: 14). 


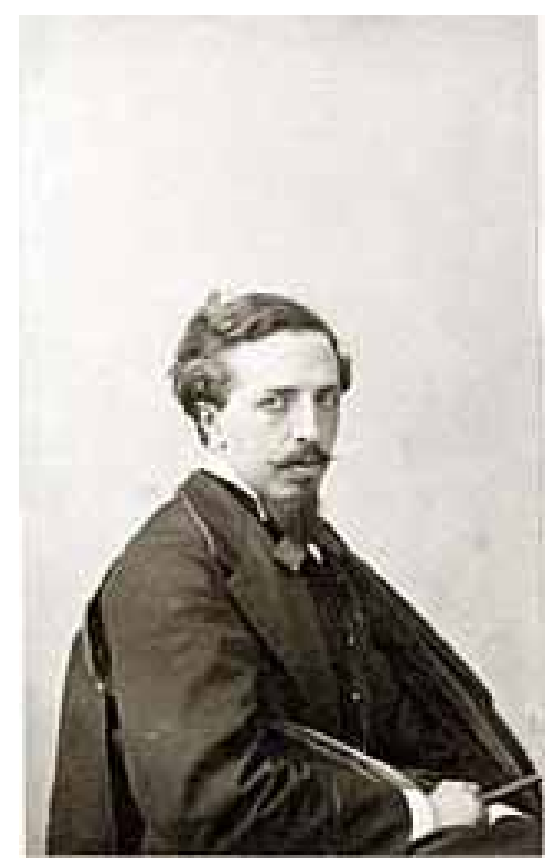

Fig. 3 - Carte de visite. Retrato del dibujante-fotógrafo de la Comisión Científica del Pacífico Rafael Castro y Ordóñez, realizado entre 1862 y 1864. ABGH000/112A/581.

los organizadores panhispanistas de la expedición que agregar un fotógrafo permitiría ver más allá a través del ojo mágico de ese emisario, pues creían que las imágenes fotográficas tenían la capacidad de "revelar todos los misterios del mundo", de "abrir los paisajes" y "traducir espacios desconocidos en escenas familiares abriendo territorios distantes a los ojos imperiales" (Ryan, 1997: 72). De manera que la incorporación de ese instrumento tecnológico añadía un elemento de prestigio a la propia expedición, convirtiéndose en un medio de propaganda del nuevo poder español al que se incorporaba la ciencia y la tecnología (Badía et al., 2000). Pero esa cámara fotográfica dotaba de agresividad a ese poder por la capacidad que tenía de ejercer hegemonía en tanto que "aportaba conocimiento estratégico de la geografía de un país que podía convertirse en campo de batalla potencial” (Ryan, 1997: 78).

Además los científicos organizadores de la expedición tenían experiencia en el uso del poder que tenía esa nueva técnica para profundizar en el conocimiento de la naturaleza y hacer circular móviles inmutables sobre las redes de comunicación científica. En la correspondencia que entabló Graells con Isidore Geoffroy Saint-Hilaire, a la que se aludió anteriormente, ambos naturalistas usaron las fotografías como instrumento de comunicación científica. De tal manera que a una petición que le hiciera el presidente de la Sociedad a principios de 1858 de enviarle un dibujo, o si era posible una fotografía, de un ejemplar de los auquénidos andinos que había introducido el rey consorte en España, junto con muestras de pelos de individuos de diferente sexo y 
edad, Graells contestó inmediatamente enviando tres fotografías de un macho y dos hembras - una de las cuales estaba criando - que adjuntaba a sus respectivas muestras de pelo-lana para que la sociedad juzgase "de la buena calidad de estos individuos de nuestro rebaño peruano" (18).

Teniendo en cuenta ese contexto no ha de extrañar pues que el dibujante de la expedición fuese provisto también de una cámara fotográfica con la que debía auxiliar en sus tareas al resto de expedicionarios. Se le ordenó sacar vistas de montañas, cortes de terreno, aspectos de la vegetación; hacer retratos de cuerpo entero de todas las razas, y representar aquellos objetos que perdiesen el colorido o se deformasen por los medios de conservación que se tuviesen que emplear - de modo que también desempeñase un papel de conservador de especímenes - , según se estipulaba en el artículo 15 del reglamento del funcionamiento de la expedición y en las instrucciones dadas a los viajeros (19).

Castro viajó entonces provisto de un complejo equipamiento procedente de París y Londres (Puig-Samper, 1988: 446-447), muestra de la dependencia tecnológica española. Durante su periplo americano hizo más de medio millar de tomas (Fig. 4).

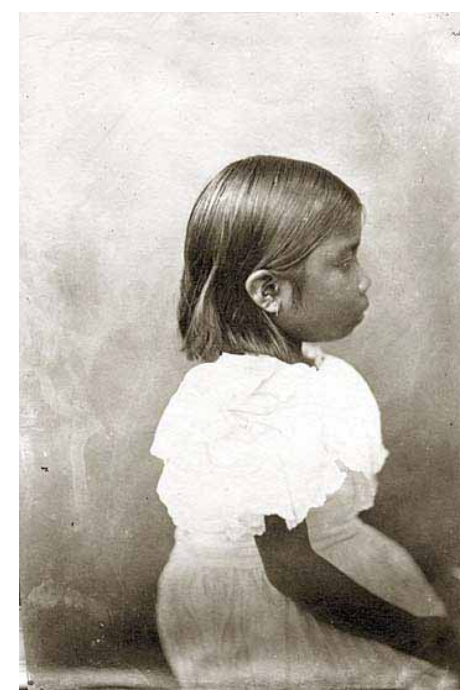

Fig. 4 - Retrato de una niña patachó, llamada Dionisia, efectuado por Rafael Castro y Ordóñez en la ciudad brasileña de San Salvador de Bahía hacia el 17 de setiembre de 1862. ABGH000/103/064.

(18) La carta de Isidore de Geoffroy Saint-Hilaire a Mariano de la Paz Graells está fechada en París el 20 de enero de 1858 y la respuesta de este a aquel en Madrid el 18 de febrero de 1858. Reproducidas en Aragón (2002), Annexe documentaire, cartas 22 y 26 respectivamente. Más adelante el 9 de octubre de 1861 Graells enviaba a Isidore Geoffroy Saint-Hilaire una nueva fotografía de dos pequeños emúes nacidos en el parque zoológico de Madrid, después de un exitoso proceso de aclimatación de sus progenitores (carta 40 del Annexe documentaire de la obra de Aragón).

(19) Tanto el Reglamento como las Instrucciones se encuentran en el Apéndice documental de Puig-Samper (1988). Ver especialmente p. 424, y 442-443. 
Pero Castro se desplazó además con un contrato con El Museo Universal. Esta publicación era la principal revista ilustrada de la España isabelina. En sus páginas colaboraban los principales fotógrafos y grabadores de aquella época. Y además tenía estrechas relaciones con Graells, como lo prueba la publicidad que se hizo en ella en mayo de 1862 del parque zoológico de aclimatación instalado en el Jardín Botánico de Madrid (20). Gracias a ese acuerdo con esa publicación, muy representativa de los gustos cosmopolitas de las clases medias emergentes de la sociedad isabelina, Castro se convirtió en un reportero del viaje y sus fotos se transformaron en móviles inmóviles que se difundieron por la esfera pública con una relativa rapidez. De manera que a través de una treintena de crónicas (Fig. 5) que envió desde las Américas a Madrid

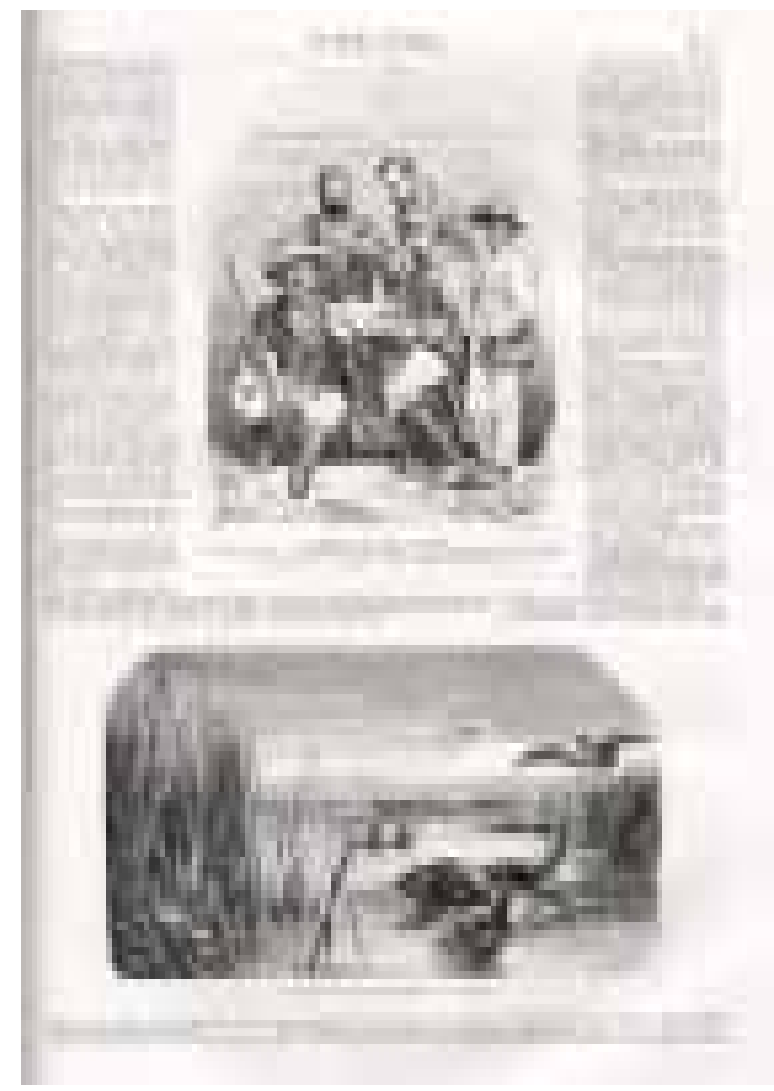

Fig. 5 - Grabado de la revista ilustrada madrileña El Museo Universal, publicado en su número del 4 de octubre de 1863 , basado en una fotografía hecha en Montevideo a fines de diciembre de $\mathbf{1 8 6 2}$ antes de que Jiménez de la Espada, Isern, Castro y Ordóñez, acompañados de un guía local, el doctor Azarola, y de un joven local, hiciesen una excursión a Solís Grande y Pan de Azúcar.

(20) En el número del 4 de mayo de 1862 aparecía un grabado acompañado de la siguiente leyenda: Madrid Moderno. Jardín Botánico. Lago y fuente rústica del Jardín Zoológico, y en el número del 11 de mayo de ese año otro correspondiente a las chozas de aves útiles al hombre existentes en ese parque de aclimatación. Reproducidos en Puig-Samper (1988: 384-385). 
durante casi dos años, ilustradas con grabados obtenidos de sus dibujos y fotografías (21), el público de la época pudo seguir las aventuras de la Comisión durante las dos primeras de las tres etapas en las que podemos dividir el periplo de ese grupo de naturalistas (Figs. 6 y 7 ).

La primera etapa abarcaría desde la salida de Cádiz del grupo expedicionario el 10 de agosto de 1862 hasta mayo de 1863 en el que toda la Comisión se reunió en Valparaiso tras haber pasado del Atlántico al Pacífico por diversas vías: un grupo cruzó las pampas y los Andes; otro usó la doble vía marítima del cabo de Hornos y el estrecho de Magallanes.

La segunda etapa fue la de la disgregación de la Comisión a causa de diversas circunstancias: tensiones que surgieron entre los comisionados y los oficiales de la fragata Triunfo, que llevaron a la dimisión de Paz como presidente de la Comisión en julio de 1863; fallecimiento del vicepresidente Fernando Amor en San Francisco de California el 21 de octubre de ese año, tras haber contraído una grave enfermedad en sus exploraciones de las minas del norte de Chile; conflictos políticos con Perú y Chile en los que se involucró la expedición naval en la que viajaban los comisionados, agravados cuando el 14 de abril de 1864 la escuadrilla español se apoderó de las islas Chincha, grandes productoras de guano, y se declaró la guerra entre el Perú y España. Los naturalistas recibieron del almirante de la escuadra naval un ultimátum para regresar inmediatamente a Europa. Puig optó por quedarse en Chile. Castro, tras hacer unas fotografías de la toma de las islas guaneras, aceptó las órdenes militares, y regresó a Madrid por la vía de Nueva York. Pero Martínez, Jiménez de la Espada, Isern y Almagro, que habían estado recorriendo precipitadamente diversos lugares de la costa del Pacífico y de los Andes bolivianos y peruanos, para formar sus colecciones, se rebelaron y buscaron la aprobación del gobierno español para emanciparse de la tutela de la escuadrilla, y organizar su propia campaña científica. Obtenido el permiso organizaron desde Guayaquil "el gran viaje": es decir atravesar la América del Sur por el paralelo 2 de latitud sur.

La tercera etapa, iniciada entre octubre y noviembre de 1864 , y en la que ya no participó el dibujante-fotógrafo Castro, fue la de la epopeya de atravesar en condiciones dificilísimas todo el continente americano desde el Pacífico hasta el puerto brasileño de Pernambuco, adonde llegaron el 25 de octubre de 1865, emulando el viaje de Francisco de Orellana, el primer navegante europeo de la cuenca hidrográfica del Amazonas. Durante ese recorrido se produjo un hecho revelador de las vicisitudes de la Comisión Científica del Pacífico: su encuentro en el puerto fluvial de Tabatinga en setiembre de 1865 con la expedición de científicos norteamericanos, liderada por Louis Agassiz, de la Universidad de Harvard, que a bordo del buque brasileño Icamiaba estaban realizando un vasto programa de investigaciones en la cuenca del Amazonas. En su Memoria Almagro evocó el contraste entre ambos grupos de científicos y cómo los naturalistas españoles se sintieron humillados:

"Nosotros estábamos derrotados completamente, sin ropa, sin zapatos, con larguísimas barbas... La intensa ictericia que tenía el pobre Isern, y todo nuestro conjunto parecía más de mendigos que de comisionados de un gobierno europeo" (Almagro, 1984[1866]: 140-141).

(21) Una relación de esas crónicas y de los grabados se encuentra en Páez Ríos (1952). 


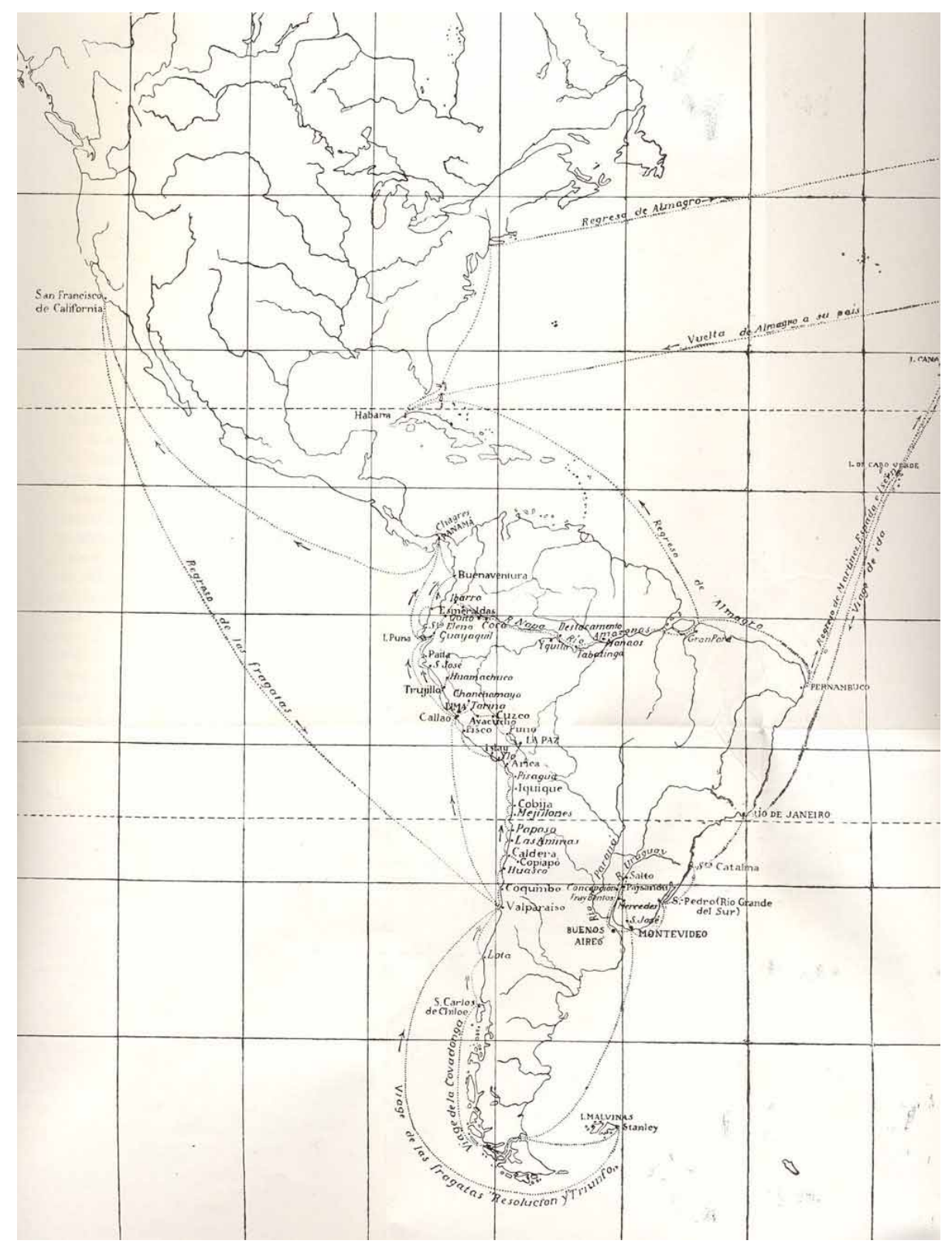

Fig. 6 - Mapa con el itinerario de los integrantes de la Comisión Científica del Pacífico, publicado en la memoria oficial redactada por Manuel Almagro titulada Breve descripción de los viajes hechos en América por la Comisión Científica enviada por el gobierno de S.M.C durante los años de 1862 a 1866, editado en Madrid en mayo de 1866. 


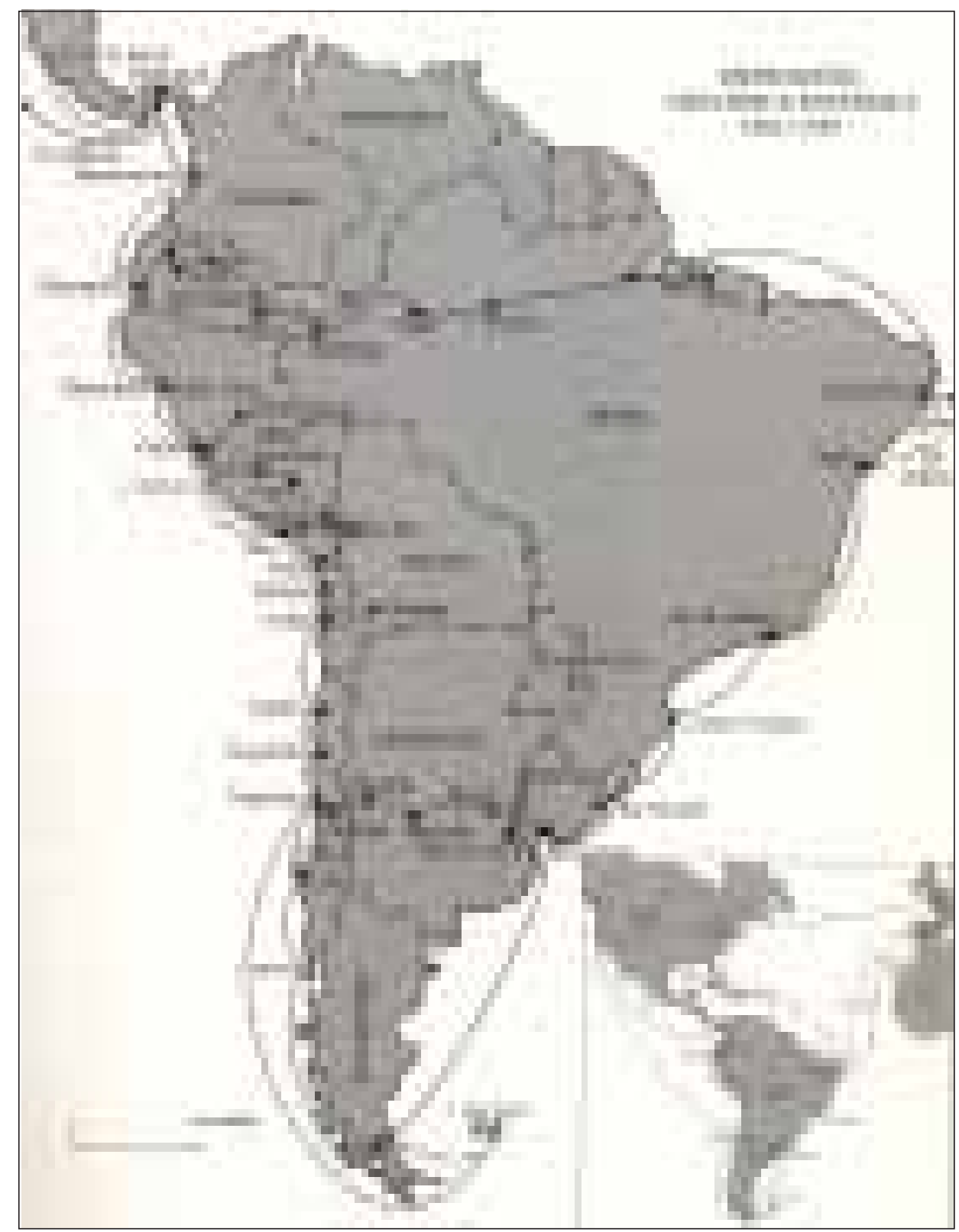

Fig. 7 - Mapa con parte del itinerario de los integrantes de la Comisión Científica del Pacífico, publicado por Robert Ryal Miller en Por la ciencia y la gloria nacional. La expedición científica española a América (1862-1866) (Barcelona, Ediciones del Serbal, 1983: 31). 
Por su parte Agassiz y su esposa, cuando escribieron su libro acerca de sus experiencias en el Brasil, también recordaron ese encuentro evocando cómo los integrantes de esa comisión científica acababan de terminar un aventurado viaje, en el que habían descendido por el Napo, en una balsa que parecía una especie de arca de Noé por la gran colección de animales vivos que trasladaban. Y rememoraban que aunque habían perdido casi toda su ropa en un naufragio afortunadamente habían logrado salvar sus notas y colecciones (22).

Es decir aquella empresa inicial que se había diseñado en el año 1862 para dar muestras de un renacimiento en España del cultivo de las ciencias naturales, y participar dignamente en el vasto programa de aclimatización del mundo promovido desde la Société Impériale Zoologique d'Acclimatation, quedaba reducida tres años después a la triste estampa de cuatro naturalistas que regresaban derrotados, y en condiciones deplorables a España. De hecho nada más llegar a Madrid, fallecería el botánico Isern en enero de 1866.

Pero el desplazamiento a tierras americanas de ese grupo de naturalistas no fue estéril. Formaron una gran colección de muestras de la naturaleza y de las culturas americanas. En el acopio de esos ejemplares desempeñaron un notable papel una legión de heterogéneos corresponsales, movilizados por las redes que desplegaron en el laboratorio americano los naturalistas españoles. En ellos había desde expertos indígenas a colectores que trabajaban para los museos europeos; desde comerciantes a naturalistas europeos y americanos implicados en la institucionalización de las ciencias naturales en la América latina. Algunos de esos colaboradores fueron premiados por el Gobierno español (Puig-Samper, 1988: 337); otros fueron salvados del olvido por los viajeros naturalistas que reconocieron el aporte local en su proceso de conocimiento. Así sucedió por ejemplo con Jiménez de la Espada, quien en diversas partes de su obra mencionó la aportación de sus colegas americanos: fuese el naturalista Philippi, que regaló a los comisionados su importante herbario chileno (Blanco \& Puig-Samper, 1995), o aquel joven amerindio, llamado Fermín, que le cazó intencionadamente en un paraje del oriente ecuatoriano un Thyroptera tricolor, ejemplar de murciélago de cierto valor científico, sobre el que volveremos más adelante.

Además a lo largo de su experiencia americana algunos de esos viajeros - como fue el caso del mencionado Jiménez de la Espada - mostraron una faz más amable del panhispanismo. Manifestaron una cierta simpatía con los logros culturales americanos, y se percataron de la importancia que tenían las diferentes tradiciones científicas existentes en la América latina para un conocimiento más cabal de su naturaleza y de su desarrollo cultural. Continuaban así una línea de trabajo preexistente entre ciertos naturalistas europeos que se desprendieron de algunos de sus prejuicios etnocéntricos al estudiar la naturaleza y las culturas americanas. Así sucedió por ejemplo con el caso del zoólogo español Félix de Azara, alguno de cuyos trabajos llevaban consigo los expedicionarios, o del propio Alejandro de Humboldt, quienes en sus trabajos revalorizaron la experiencia acumulada por los americanos en su proceso de autoconocimiento. De ahí no ha de extrañar que en el segundo punto de las instrucciones

(22) Louis Agassiz y Elizabeth Cabot Agassiz, 1895 - A journey in Brazil: 208; Boston, citado por Miller (1983: 232). 
botánicas que se les dieron se les pidiese que averiguasen no sólo las particularidades que ofreciesen las plantas, y sus usos, sino también los nombres dados por las poblaciones amerindias (Puig-Samper, 1988: 421).

De hecho, en medio de todas las dificultades en las que se vieron envueltos, esos expedicionarios enviaron más de ochenta mil muestras de la naturaleza y de las culturas americanas a Madrid, donde el 3 de mayo de 1863 se había creado una comisión para hacer de nudo de las redes desplegadas por los viajeros naturalistas ya que su objetivo era recoger, ordenar y colocar en el Museo de Ciencias Naturales los objetos que remitiese la comisión de Profesores de Ciencias Naturales del Pacífico (PuigSamper, 1988: 333-337).

Unos envíos fueron más fáciles de hacer que otros: el grado de dificultad para desplazar a objetos, susceptibles de ser transformados en móviles inmutables, por redes de comunicación es variable. La primera gran remesa efectuada por los viajeros naturalistas se hizo en noviembre de 1862 desde Río de Janeiro y llegó a Madrid sin dificultades (23). Pero otro envío posterior efectuado desde Valparaíso en octubre de 1864 estuvo plagado de problemas, dadas las dificultades para mantener estables las redes al encontrarse los viajeros naturalistas casi aislados por las dificultades políticas que habían surgido entre España y las repúblicas americanas del Pacífico sudamericano. Con destino al parque zoológico de aclimatación del Jardín Botánico de Madrid, Jiménez de la Espada decidió enviar ochenta y seis mamíferos y aves entre los que había desde cóndores a machos y hembras de guanaco y liebres de la Patagonia. Tuvieron que ser embarcados en la fragata francesa Persévérance rumbo a Le Havre. Y de allí emprendieron un azaroso viaje a Madrid, de manera que no todos llegaron vivos a su destino. A pesar de que algún autor ha considerado ese traslado una "tragedia zoológica" (Miller, 1983: 166-167) inmediatamente Graells hizo publicidad a sus consocios de la Société Impériale Zoologique d'Acclimatation del valor de animales tan exóticos, sobre todo de la liebre de Patagonia (24). Y como resultado de esa campaña publicitaria dicha Sociedad en su sesión plenaria anual celebrada el 23 de marzo de 1866 en el Hotel de Ville de París condecoró a Jiménez de la Espada con una Medalla de primera clase de la división de mamíferos, por haber traído a Europa de sus viajes a la América meridional numerosas especies animales. De esa recompensa enseguida se hizo eco la prensa española en un tono vindicativo (25) aunque ciertamente meses después sólo sobrevivían diez de esos animales: cuatro huanacos, dos liebres de Patagonia, un carnero, dos ovejas de la Ligua y un coipu (Almagro, 1984[1866]: 171).

(23) Ese envío estaba formado por 808 ejemplares de moluscos, 538 especies con 3600 ejemplares de plantas de Canarias, Cabo Verde y Brasil, 11913 ejemplares de muestras geológicas e insectos, 103 reptiles, 13 mamíferos, 1007 ejemplares de aves, con cuatro nidos y varios huevos, y una colección etnográfica formada por diversas armas y objetos de adorno, y una cabeza momificada por indios brasileños. Ver Puig-Samper (1988: 334).

(24) Ver "Sur les travaux d'acclimatation en Espagne en 1864. Lettre adressée à M. le Président de la Société impériale d'acclimatation. Par M. Graells, délégué de la Société impériale d'acclimatation à Madrid le 24 janvier 1865", publicada en el Bulletin de la Société impériale zoologique d'acclimatation (1865: 15-18).

(25) Ver por ejemplo el diario Irurac bat de Bilbao del domingo 11 de marzo de 1866 (año $\mathrm{XV}, \mathrm{n}^{\circ}$ 56: 3, col. 1). 
Pero las colecciones acumuladas por esos expedicionarios no sólo se desplazaron hacia los nodos europeos. También algunos móviles inmutables generados por esos expedicionarios circularon en el interior de las sociedades americanas. Y es así como algunas de las fotografías hechas por Castro en sus excursiones por California en octubre de 1863 fueron incluidas como reproducciones litrográficas por Edward Vischer en algunas de sus obras (26). En su libro Sequoia Gigantea, Calaveras Mammoth Tree Grove, hechas a partir de internegativos del fotógrafo George H. Johnson, Vischer publicó tres de esas fotografías como subraya Palmquist (27). Una cuarta fotografía hecha por Castro en esa excursión por tierras de Estados Unidos - de las 32 que conserva el CSIC de su colección californiana (28) - , fue reproducida también por Vischer con el título Mining Scene Near Murphy en su libro Pictorial of California, publicado en San Francisco en 1870.

No sabemos si Castro y Ordóñez supo de la primera circulación de sus fotografías, transformadas en móviles inmutables, entre el público californiano y norteamericano a partir de 1864, pues meses después de llegar a Madrid procedente de Nueva York se suicidó a finales de 1865 , por razones aún confusas, pero que confirman el pathos romántico en el que estuvo envuelta esa comisión y el halo trágico que la acompañó.

Agrupados en Madrid los supervivientes de la expedición a principios de 1866, los patronos políticos y científicos que habían financiado y organizado la exploración llevada a cabo por los viajeros naturalistas, quisieron exhibir los resultados acumulados por esa especie de argonautas modernos, cuyo vellocino de oro era una impresionante muestra de la biodiversidad de la naturaleza americana y de su pluralidad cultural. Organizaron entonces una gran exposición en el Jardín Botánico de los objetos recolectados por los integrantes de la Comisión Científica del Pacífico durante su periplo americano (Barreiro, 1926: 406-411; Miller, 1983: 239-244; Puig-Samper, 1988: 339345). Lo que no sabían organizadores, exhibidores y visitantes de esa exposición es que a partir de entonces, y durante casi siglo y medio, las colecciones que se exhibían en aquel espacio iban también a tener una circulación complicada por las redes de comunicación científica, según vamos a intentar mostrar en las páginas siguientes.

\section{LAS DISCONTINUIDADES DE UN CONJUNTO DE COLECCIONES AMERICANAS}

La mencionada exposición tuvo al parecer un cierto éxito de público (Fig. 8). Diversos medios de comunicación hicieron de portavoces de la labor desplegada por los integrantes de la Comisión Científica del Pacífico. Entre ellos destacó El Museo Universal. Su director-propietario, José Gaspar, obsesionado por su labor de mediación entre los científicos isabelinos y sus públicos, solicitó autorización para que uno de los

(26) Sobre las relaciones entre ese artista bávaro y los comisionados españoles ver Miller (1983: 143, 145).

(27) Edward Vischer (1864), prefacio, citado por Palmquist (1982: 15).

(28) La totalidad de esa colección californiana custodiada por el CSIC se puede ver en Molina et al. (2000) y en el sitio de Internet www.pacifico.csic.es 


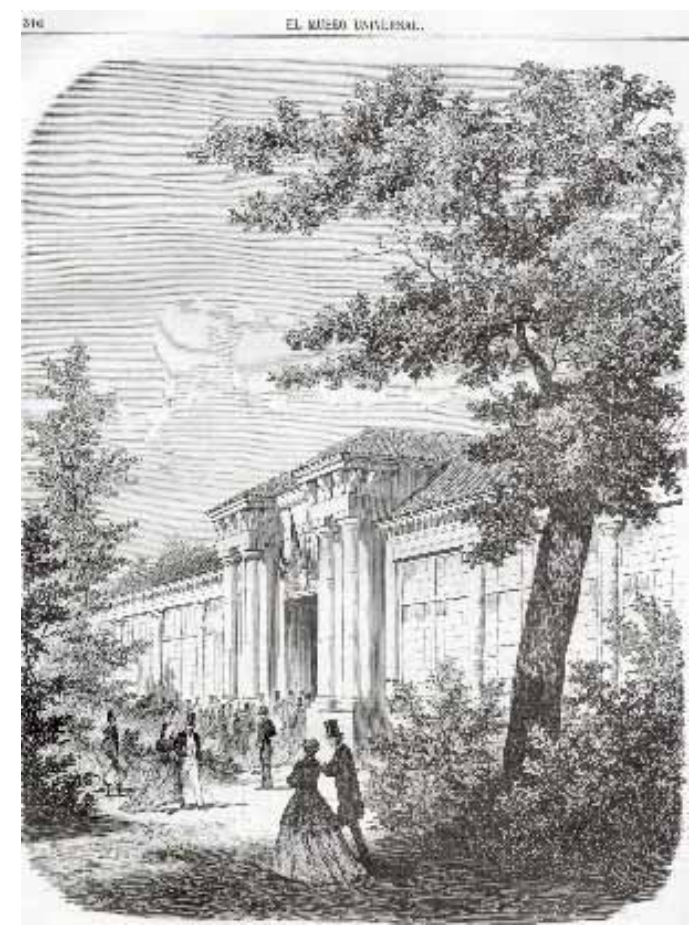

Fig. 8 - Grabado de la revista ilustrada madrileña El Museo Universal, publicado en su número del 7 de octubre de 1866, alusivo a los visitantes que contemplaron la exposición celebrada en el Jardín Botánico de Madrid sobre las colecciones de la Comisión Científica del Pacífico, y que tuvo lugar entre mediados de mayo y finales de junio de 1866.

dibujantes de la revista entrase en el recinto de la exposición y copiase los objetos expuestos a fin de darlos a conocer entre sus lectores (29). Varios grabados con algunas de las muestras exhibidas aparecieron en efecto en las páginas de esa revista, transformada en una especie de museo portátil (Fig. 9). También aparecían curiosos que se deleitaban observando las maravillas exhibidas en aquella especie de teatro de la naturaleza y de las culturas americanas.

Algunos de esos visitantes nos son conocidos. Uno de ellos fue el vasco José María Murga, un propietario de Bilbao que se había hecho miembro de la Sociedad imperial zoológica de aclimatación en 1859. Jiménez de la Espada lo guió y le enseñó un curioso ejemplar de un murciélago: un Thyroptera tricolor. Otro, una mujer que escribió un poema de corte romántico en una revista destinada al consumo familiar

(29) Carta de José Gaspar a Mariano de la Paz Graells. Archivo del Museo Nacional de Ciencias Naturales. Documentos Comisión Científica del Pacífico. In Calatayud (1984: documento 738). 


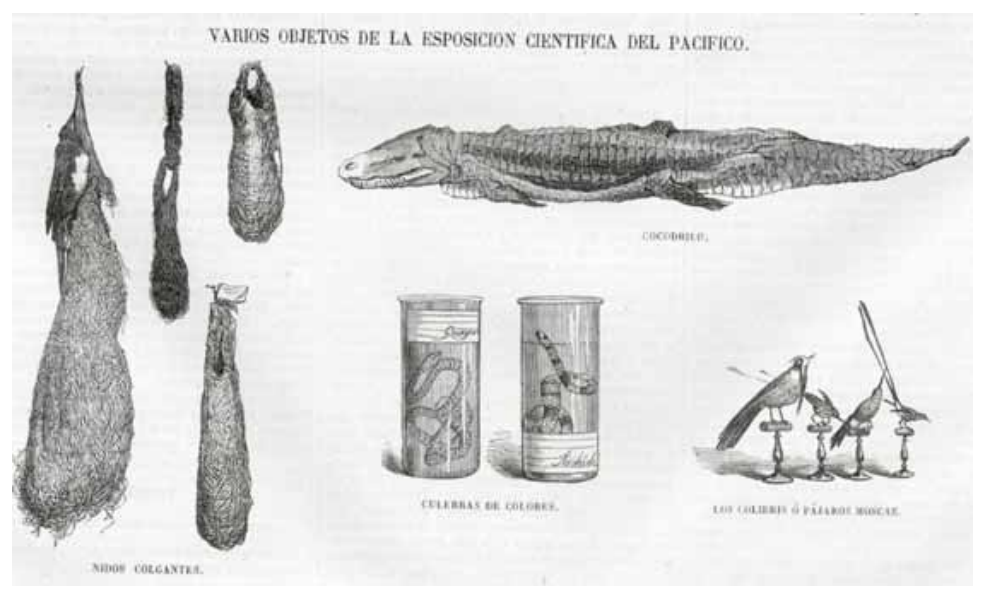

Fig. 9 - Grabado de la revista ilustrada madrileña $E l$ Museo Universal, publicado en su número del 28 de octubre de 1866, con diversos objetos de las colecciones de la Comisión Científica del Pacífico exhibidos en la exposición que tuvo lugar en el Jardín Botánico de Madrid, como nidos colgantes, culebras de colores, colibríes, y un cocodrilo.

tras quedar sobrecogida por la visión de una amplia colección de momias precolombinas, procedentes de tierras bolivianas y peruanas y de la isla chilena de Chiloé (30).

Dado ese éxito de público, que adquirió más de medio millar de ejemplares de la memoria oficial del viaje que redactara el antropólogo de la Comisión Almagro, parecía que existían condiciones favorables para iniciar el estudio sistemático de las colecciones. Pero la realidad fue bien distinta. Esa exposición fue el canto de cisne de la ciencia isabelina. Ciertamente mientras se organizaba la exposición se creó la Comisión de estudios de las colecciones del Pacífico. Pero nació con mal pie. Los políticos se mostraron cicateros. Se solicitó a Martínez, Espada y Almagro que elaborasen una magna obra en la que se diesen a conocer los nuevos géneros y especies contenidos en la inmensa colección traída de tierras americanas, y se les exigió que presentasen resultados en un plazo de dos años. Pero precisamente durante esos dos años, en un proceso paralelo a la crisis de la monarquía isabelina, que finalizó con el destronamiento de Isabel II en setiembre de 1868, se produjo también una crisis en la ciencia isabelina. Graells perdió el poder en el Museo de Ciencias Naturales en 1867 y su caída en desgracia supuso el debilitamiento del programa de aclimatación y la pérdida de impulso a todo el plan de trabajo que había originado el envío de la Comisión Científica del Pacífico a tierras ultramarinas.

Fue a partir de 1869, tras la llegada al poder de una coalición de fuerzas liberales interesadas en el fomento de la ciencia (López-Ocón, 1997), cuando se reactivaron las

(30) Domingo y Soler (1866: 278-279). Agradezco a Carolina Martín, conservadora del Museo Nacional de Ciencias Naturales el habernos transmitido esta información. 
tareas de la Comisión de estudios de las colecciones del Pacífico. La colección de moluscos, compuesta de 38755 ejemplares, correspondientes a 816 especies, fue estudiada por Martínez y sobre todo por el principal malacólogo español de aquella época González Hidalgo, colaborador del prestigioso Journal de Conchyliologie. Entre ambos describieron en tres publicaciones editadas a lo largo de una década diversas especies. El primero se concentró en los bivalvos marinos y el segundo en los gasterópodos marinos y terrestres, los cuales dio a conocer en 1872 en un libro ilustrado con ochenta y nueve figuras ejecutadas por los hermanos Becquet, litógrafos de París (Gonzáles Hidalgo, 1872; 1879; Martínez y Saéz, 1869). Según la última estudiosa del material malacológico recogido durante la expedición al Pacífico los expedicionarios recogieron 324 especies de gasterópodos marinos y 241 de terrestres, de las que González Hidalgo logró describir 19 nuevas especies, junto a una especie nueva de gasterópodo marino, dos especies de gasterópodos de agua dulce, y dos de bivalvos de agua dulce (Calvo, 1994: 283-285).

Pero hubo otros aportes al conocimiento de esa colección, dada su riqueza y variedad. Cuando regresó a Madrid, Paz que había sido presidente de la Comisión, envió material de bivalvos dulceacuícolas al norteamericano Isaac Lea de la Academia de Philadelphia, quien inmediatamente describió catorce especies nuevas, aunque no indicó las localidades tipo de las mismas (31). Medio siglo después sería un investigador alemán Friedrich Haas, quien se desplazara a Madrid para completar las investigaciones iniciadas por Lea sobre los bivalvos dulceacuícolas obtenidos por los integrantes de la Comisión Científica del Pacífico. Basándose en una distribución geográfica del "botín recogido" por los expedicionarios hizo reflexiones zoogeográficas sobre su distribución al señalar que las aguas sudamericanas del Pacífico no tenían ninguna especie común con las del Atlántico, y que la cuenca del Río de la Plata y la del Amazonas y los sistemas fluviales al Norte de éste, ofrecían muy pocas especies comunes (Haaas, 1916: 41, 61).

La obra científica más relevante relacionada con la expedición al Pacífico fue no obstante la desplegada por Jiménez de la Espada. El fue el único de los comisionados que permaneció obsesionado durante tres décadas — hasta su fallecimiento en 1898 con el conocimiento de las tierras y las culturas que observó durante su periplo americano.

En un primer momento su plan de trabajo se centró en el estudio de los mamíferos que había recogido y observado en su viaje por el alto Amazonas, región de una biodiversidad extraordinaria. Viajó a París. Contactó con diversos colegas como los Milne-Edwards, padre e hijo, Dumeril, J. Verreaux, Gervais y Braconnier, y cotejó las colecciones que estaban a su cargo con los tipos más interesantes de la fauna sudamericana que había en su Museo de Historia Natural. A su regreso, combinando sus conocimientos de anatomía comparada y de fisiología intentó describir nuevas especies de monos, destacando además los mecanismos de adaptabilidad desarrollados por algunos

(31) Ver Proceedings of the Academy of Natural Sciences of Philadelphia (1866), vol. X. Lea amplió el estudio de esas especies en el volumen VI del Journal of the Academy of Natural Sciences of Philadelphia (1868) y en sus "Observations on the genus Unio", ibid., vol. XII, (1869). Información tomada de Calvo (1994: 286). 
mamíferos para su vida arbórea, como era el caso de las ventosas del Thyroptera tricolor Spix, que había cazado para él un joven indígena en el oriente ecuatoriano el 25 de mayo de 1865, "ya que un mamífero con ventosas era para nosotros el hallazgo más extraordinario hasta entonces de nuestro viaje, y un descubrimiento raro en la anatomía de esos vertebrados" (32). Había en ese tex to un interés en dar cuenta de la distribución de las especies observadas y de su comportamiento. Publicado el artículo lo envió a Murga, aquel visitante de la exposición en el Jardín Botánico a quien le había enseñado el murciélago en 1866, contestándole ese lector que "la descripción del murciélago con ventosas es una cosa curiosísima y que tiene la circunstancia, no muy común, de que pueden entenderla lo mismo los sabios como los legos. Recuerdo perfectamente el ejemplar que me hizo V. ver en la Exposición" (33) (Fig. 10).

Ahora bien, obsesionado por alcanzar la prioridad en sus descubrimientos, y por convencer a sus colegas de la importancia de su cosecha científica, Espada se

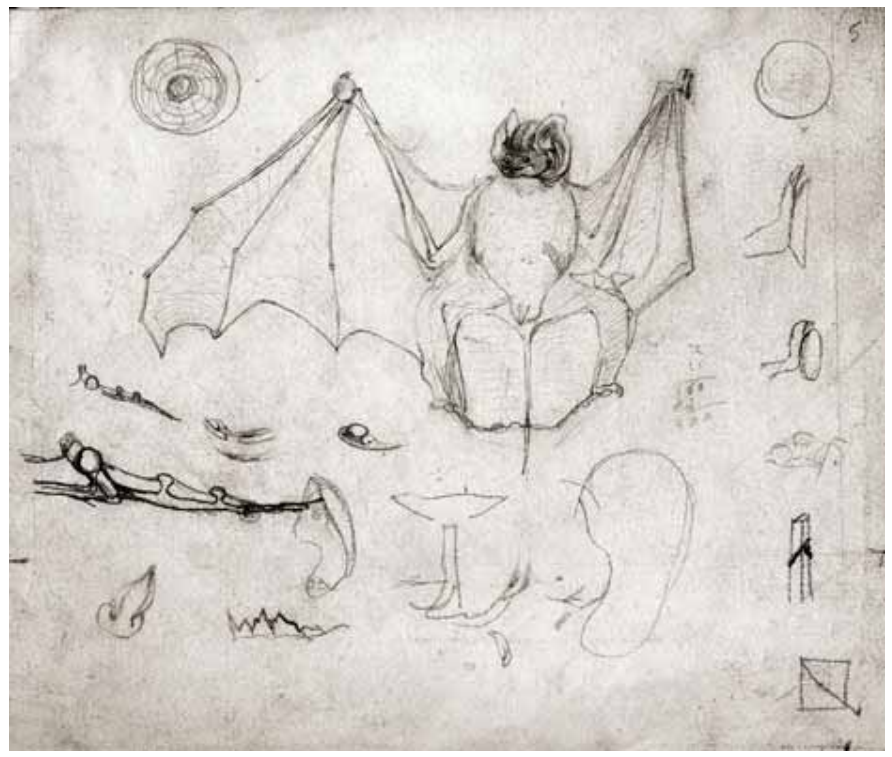

Fig. 10 - Dibujo a grafito de un ejemplar de Thyroptera tricolor, Spix que Jiménez de la Espada obtuvo en Baeza de los Quijos, en el oriente del Ecuador, hacia el 25 de marzo de 1865, y cuyas peculiaridades anatómicas y hábitat estudió en su monografía Algunos datos nuevos o curiosos acerca de la fauna del alto Amazonas. Mamíferos, publicada en el Boletín-Revista de la Universidad de Madrid, 1870. Ese dibujo se encuentra en ABGH000/200/675.

(32) Jiménez de la Espada, 1870 - Algunos datos nuevos o curiosos acerca de la fauna del alto Amazonas, Boletín-Revista de la Universidad de Madrid. Reproducido en López-Ocón \& PérezMontes, eds., (2000: 213).

(33) Carta de José María de Murga a Marcos Jiménez de la Espada, Marquina 8 de mayo 1870. Fondo Marcos Jiménez de la Espada de la Biblioteca General de Humanidades del CSIC. Accesible a través de Internet en la dirección www.csic.es/cbic/BGH/espada/pagina.htm 
concentró en los años siguientes en el estudio de la colección de 786 ejemplares de anfibios que logró reunir durante su viaje. Contactó entonces con una red de herpetólogos europeos y norteamericanos y en cinco sucesivas publicaciones, de carácter taxonómico en su mayor parte, dio a conocer los resultados de sus investigaciones. Fruto de su voluntad de dar a conocer la originalidad de sus trabajos publicó el primero de sus trabajos en latín en el órgano de expresión de la Academia de Ciencias de Lisboa (Jímenez de la Espada, 1870), que dirigía el zoólogo portugués José Vicente Barboza du Bocage. Esa conexión le permitió a Espada entrar en contacto con otros colegas europeos y norteamericanos como Günther, del British Museum, G. Elliot, de la Zoological Society of London y E. Cope, secretario de la Academia de Ciencias Naturales de Filadelfia, con quien se relacionó por intermedio de Barboza du Bocage, que parecía ejercer la función de nudo de una red en la que procuró insertarse Espada (34). Los estudios herpetológicos de Espada culminaron con la edición de su obra cumbre en 1875: un volumen de 208 páginas y siete magníficas láminas debidas a Díaz Carreño, un notable artista al que Espada convenció para que se dedicase al dibujo científico (Fig. 11). Según se ha señalado recientemente (De la Riva, 2000: 80) el libro contiene en su texto la redescripición de 18 géneros y 24 especies previamente conocidos de anfibios sudamericanos, y la descripción de 2 géneros, 12 especies y 3 subespecies nuevos, así como, en algunos casos, observaciones interesantes sobre la biología de las especies. Ha sido considerado este trabajo tan importante por los herpetólogos estudiosos de la fauna neotropical que la Society for the Study of Amphibians and Reptiles de Estados Unidos, por iniciativa del conocido herpetólogo Jay M. Savage, y en colaboración con el gobierno español, decidió reeditarla en 1978 (Savage, 1978). A lo largo de la elaboración de esa compleja obra dialogó con los trabajos de casi todos los estudiosos de los anfibios sudamericanos coetáneos, o que le habían precedido en sus investigaciones herpetológicas, como fue el caso, por ejemplo, del viajero naturalista francés Alcide d'Orbigny (Jiménez de la Espada, 1978[1875]: 44, 47, 188).

Jiménez de la Espada no se limitó a hacer estudios taxonómicos, siguiendo la metodología de Cuvier, en la que se había formado. En 1872 y en las páginas del órgano de expresión de la Sociedad Española de Historia Natural, que contribuyó a fundar en 1871, y de la que fue un animador en sus primeros años de existencia, publicó un estudio sobre la reproducción de la rana Rhinoderma Darwinii, una de las dos especies que componen la familia Rhinodermatidae, y que tienen una limitada distribución en los bosques templados de Chile y parte de Argentina. Como ha subrayado De la Riva (2000: 79) Espada hizo entonces un importante descubrimiento y rápidamente comprendió su magnitud en el contexto de la biología evolutiva. El naturalista francochileno Gay (1848) había establecido que esta rana era vivípara porque había hallado

(34) En el mencionado fondo Jiménez de la Espada de la BGH del CSIC se encuentran las siguientes cartas dirigidas a Jiménez de la Espada: 13 de Barboza du Bocage, fechadas en Lisboa 13 noviembre 1869, 3 y 19 de marzo, 11 y 17 de mayo, 17 de julio de 1870, 25 mayo y 3 de junio 1871, 16 de febrero y 4 de marzo de 1872, 15 de noviembre, 30 de diciembre 1874, 13 de julio 1875; 2 de A. Günther, fechadas en Londres el 26 de mayo de 1871 y el 9 de octubre de 1875; 4 de G. Elliot, fechadas en Londres 13 de junio y 21 de setiembre y Ginebra 29 de junio de 1871 y Paris 21 de agosto de 1875. Un análisis más amplio del significado y características de esa correspondencia en López-Ocón (1991: 408-418). 
Viage al Pacilito, Batrácios anuvs. Lam. 6.

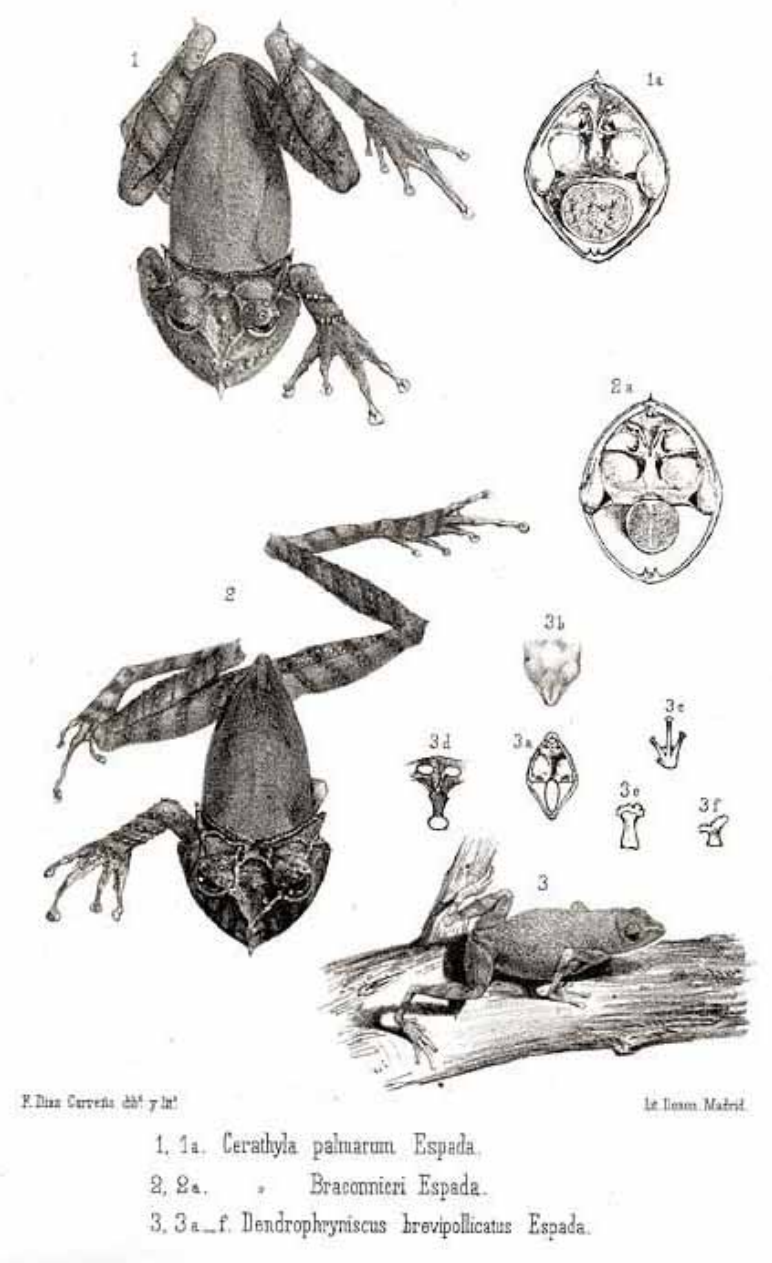

Fig. 11 - Lámina correspondiente a la gran obra herpetológica de Marcos Jiménez de la Espada, Vertebrados del viaje al Pacífico. Batracios, editada en Madrid en 1875, y reeditada por la Society for the Study of Amphibians and Reptiles en 1978, donde se representan algunas especies de anfibios de la América neotropical.

renacuajos bien formados en el interior de ejemplares que tenían que ser hembras. Pero Espada observó que son los machos los que transportan a las larvas en el interior de sus sacos vocales. Al tener que hacer sus observaciones en ejemplares preservados, puso de manifiesto la importancia que tendrían futuros estudios con ejemplares vivos para terminar de comprender cómo se produce tan extraña modalidad reproductora, que sigue estando entre las más interesantes conocidas en los anfibios anuros dentro de su tendencia evolutiva hacia la independización del medio acuático. Esa monografía 
de Espada, a pesar de estar escrita en español, traspasó la frontera de los Pirineos y suscitó la curiosidad de colegas europeos. Y es así como J.W. Spengel en 1877 hizo de portavoz de Espada entre los lectores de la Zeitschrift für Wissenschaftliche Zoologie al traducir parte de su artículo al alemán y al ubicar su contribución en la literatura zoológica de la época (Spengel, 1877).

Ahora bien cuando Jiménez de la Espada parecía haber alcanzado la madurez como zoólogo y empezaba a adquirir reconocimiento entre sus pares, como prueba la mencionada crítica favorable del citado Spengel, así como la que efectuara el nuevo líder de la zoología española Pérez Arcas a su obra cumbre sobre los anfibios sudamericanos (35), decidió dar un giro a su programa de investigaciones. Emprendió entonces nuevos derroteros transformándose en un historiador americanista. Esa reorientación de su mirada hacia el pasado se debió a varias razones. Una de ellas fue que decidió enriquecer sus investigaciones sobre sus colecciones con la práctica textual sobre un corpus de conocimientos previos. Localizó entonces una tradición científica que le interesó rescatar por motivos nacionalistas.

Este recurso a la práctica textual fue común a muchos naturalistas del siglo XIX. Fa-ti Fan ha mostrado recientemente cómo los integrantes de la North China Branch of the Royal Asiatic Society interpretaron y trasladaron el conocimiento existente en los textos chinos sobre el mundo vivo para avanzar en su conocimiento de la naturaleza de aquella civilización milenaria (Fan, 2000). Pues bien hubo otro grupo de naturalistas - procedentes muchos de ellos de la ciencia humboldtiana, como Jiménez de la Espada - , que recurrieron al uso de la evidencia textual, del dato filológico y de los documentos históricos para sus investigaciones naturalistas. Y fue esa práctica la que condujo a Espada a insertarse en un nuevo campo de conocimiento: el del americanismo. Para ello participó activamente en una serie de congresos internacionales (Bruselas 1879, Madrid 1881, Turín 1886, Berlín 1888 y París 1890) en los que se fue construyendo ese nuevo campo científico (López-Ocón, 2000b; 2002), y elaboró una singular obra historiográfica destinada a dar a conocer fuentes históricas relevantes para el conocimiento de la naturaleza y de las antiguas culturas americanas (Bustamante, 2000). En el transcurso de esos estudios americanistas volvió a encontrase una vez más con la obra de Alcide d'Orbigny, cuyo trabajo L’homme américain leyó con atención como se puede apreciar entre sus notas de trabajo sobre los desplazamientos de los "caribes" por tierras sudamericanas (36). Uno de los hitos de su producción historiográfica fue sin lugar a dudas la publicación en cuatro volúmenes de las Relaciones Geográficas de Indias, dedicadas al virreinato del Perú, que editó entre 1881 y 1897 , y en cuyo segundo volumen - de 1885 - , dio a conocer importantes documentos, de carácter geográfico y etnográfico, sobre el territorio y las poblaciones de la actual Bolivia, como la "Relación de la provincia de los Pacajes", o la "Relación

(35) Laureano Pérez Arcas, Nota, en Actas de la Sociedad Española de Historia Natural. Sesión de 1 de marzo de 1876, Anales de la Sociedad Española de Historia Natural, vol. V: 35-39. Reproducido en López-Ocón \& Pérez-Montes (2000: 335-337).

(36) Ver por ejemplo en el fondo Jiménez de la Espada del Archivo de la Biblioteca General de Humanidades del CSIC el documento ubicado en ABGH0004/04/000. 
muy particular del cerro y minas de Potosí y de su calidad y labores, por Nicolás del Benino, dirigida a don Francisco de Toledo, virey del Perú en 1573”.

Una gran parte de esa obra tuvo un gran impacto entre sus coetáneos hispanoamericanos, particularmente peruanos - pero también chilenos como José Toribio Medina o bolivianos como Gabriel René Moreno-, que hicieron suyos parte de los logros historiográficos de Jiménez de la Espada, como lo prueba la importante condecoración que le diera el gobierno del Perú en 1892, o la amplia participación de científicos e intelectuales limeños, promovida por Ricardo Palma, en la campaña de solidaridad con la familia de Jiménez de la Espada tras la muerte de éste en 1898 (Del Pino, 2000; LópezOcón, 2000c), en una muestra de la existencia de una ciencia federativa iberoamericana a fines del siglo XIX, que ha tenido posteriormente durante el siglo XX manifestaciones diversas (Acosta et al., 2003). La obra historiográfica de Espada ha sido estimada a lo largo de ese siglo XX por variados lectores, inspirando estudios clásicos, como el de John Murra sobre las estructuras socioeconómicas del imperio Inca (1978), e impulsando la creación de la disciplina de la etnohistoria andina (37), según pude constatar durante mi participación en la Primera Maestría en Historia Andina organizada por la sede de Quito de FLACSO durante el curso académico 1984-1985.

Mientras Jiménez de la Espada culminaba su programa de investigaciones historiográficas, en la década de 1890 iniciaba sus estudios sobre las colecciones antropológicas recogidas por Manuel Almagro en el viaje al Pacífico Luis de Hoyos y Sáinz, quien a lo largo de más de un cuarto de siglo realizaría diversas publicaciones (1910; 1911a; b; c; 1913; 1923-1924a; b), en las que estableció una tipología de la deformación craneana y aportó numerosos datos antropométricos sobre los habitantes de la región andina, considerados útiles y precisos aún hoy en día (Puig-Samper, 1988: 367).

De todas maneras fue el legado de Jiménez de la Espada, y su particular discurso híbrido entre las ciencias naturales y la historia, así como la colección fotográfica de Castro y Ordóñez, los que actuaron de portavoces de la ciencia procesionaria de la Comisión Científica del Pacífico durante el siglo XX.

En sus últimos años de vida Espada logró transmitir sus conocimientos sobre la colección de mamíferos de esa expedición a su discípulo Angel Cabrera (1879-1960). Este zoólogo, entre 1900 y 1913, en un momento de revitalización de las actividades del Museo de Ciencias Naturales, realizó una serie de trabajos en los que descubrió ocho especies nuevas y cinco subespecies (Cabrera, 1900; 1901a; b; c; 1904; 1907; 1913; 1917) (38). Ese entrenamiento de Cabrera con las colecciones del Pacífico le permitió familiarizarse con la fauna sudamericana, de la que se convertiría en un gran experto cuando se estableció en Argentina para trabajar en el Museo de la Plata. Poco después, durante la década de 1920, resurgió el interés por la Comisión Científica del

(37) Al respecto, Murra comentó: “The one important scholar in this field was Marcos Jiménez. de la Espada, who was most active a hundred years ago while earning his living a curator of amphibians at Madrid's Museum of Natural History. As a sideline he published the sources Prescott had used in manuscript form and others the New Englander had never seen" (Murra, 1984 : 61).

(38) Una valoración de sus trabajos en Referencias a sus aportaciones al conocimiento de la fauna argentina en García-Perea \& Gisbert, 1998. Referencias a sus aportaciones al conocimiento de la fauna argentina en www.paleonet.com.ar:8080/biografias/acabrera/acabrera.html 
Pacífico, gracias a los trabajos historiográficos que emprendió Barreiro, quien, entre otras iniciativas, editó las partes del diario de Espada que conservaban sus herederos (Barreiro, 1928), recuperó las notas botánicas de Isern y promovió la celebración en 1929 nuevamente en el Jardín Botánico de Madrid de una "Exposición Retrospectiva de Historia Natural", en la que se exhibieron parte de las colecciones de las expediciones que naturalistas españoles habían realizado a tierras americanas y oceánicas.

Esa exhibición suscitó un cierto interés en la opinión pública madrileña. De hecho muy poco después un héroe de la aviación, el capitán Francisco Iglesias, convenció a las nuevas autoridades de la Segunda República española para organizar una nueva expedición científica al Alto Amazonas, en la que se rememorasen en cierta medida las aventuras de la Comisión Científica del Pacífico (39). Pero sobre todo contribuyó a revitalizar el estudio científico de algunas colecciones. Así sucedió con el estudio que hizo el botánico catalán Josep Cuatrecasas (1903-1996) del herbario de Isern en su estancia en el Jardín Botánico de Berlin entre el 7 de diciembre de 1934 y el 20 de febrero de 1935, donde contó con la colaboración de los profesores Pilger, Diels, y Mattfeld (Cuatrecasas, 1935).

No obstante los condicionantes políticos volvieron a interferir en el desarrollo del estudio de las colecciones del Pacífico. En julio de 1936 el general Franco se sublevó y se inició una cruenta guerra civil. Uno de los científicos republicanos que partió al exilio fue Cuatrecasas que, primero en Colombia y luego en el Departamento de Botánica de la Smithsonian Institution de Estados Unidos, desarrollaría un importante programa de investigaciones en flora tropical (40). Entretanto las colecciones del Pacífico sufrieron una nueva etapa de desinterés durante la dictadura franquista.

La atención se volvió a concentrar en ellas gracias a dos hallazgos que se hicieron en las dos últimas décadas del siglo XX en una nueva fase de recuperación del sistema científico español. Primero en la década de 1980 se redescubrieron en el Museo de Ciencias Naturales de Madrid parte de las placas de vidrio hechas por el fotógrafo Castro durante su viaje americano. Se efectuó entonces un proceso de restauración que culminó con una exposición realizada en 1992 (Calatayud \& Puig-Samper, 1992), y en esa institución se retomó el interés por el análisis de las colecciones zoológicas reunidas por aquellos expedicionarios románticos del siglo XIX, publicándose en 1994 un catálogo de la colección de insectos (Santos Mazorra, 1994). Paralelamente en el Jardín Botánico se retomó el interés por el estudio del herbario de Isern (Blanco \& Rodrígez, 1996; Blanco, 1998). Y en 1995 se encontró en la Biblioteca General de Humanidades del CSIC lo que se ha denominado el "tesoro oculto de Jiménez de la Espada", es decir el fondo iconográfico de ese naturalista historiador que se custodiaba en ese lugar de la

(39) Ver por ejemplo Iglesias, 1931. Un reciente estudio en el que se analizan en detalle las causas del fracaso de esa expedición que no logró salir de la Península Ibérica rumbo a América (López Gómez, 2002).

(40) Sobre las aportaciones colombianas de Cuatrecasas ver Pinto-Escobar, Poliodoro "José Cuatrecasas y la flora y la vegetación" en www.banrep.gov.co/blaavirtual/letra p/pacific1/cap13.htm; de la importancia de su labor en Estados Unidos da idea que en su honor la Smithsonian Institution ha establecido The José Cuatrecasas Botanical Endowment Fund y la José Cuatrecasas Medal for Excellence in Tropical Botany. 
memoria. Ese fondo, formado por más de medio millar de fotografías hechas por Castro o conseguidas por los expedicionarios durante su periplo americano, de las que unas 70 son únicas de ese fondo, y por más de un centenar de dibujos y láminas, no sólo ha permitido revelar nuevos aspectos del proceso de conocimiento de su poseedor, sino que ha permitido poner en marcha una original iniciativa para preservar y recuperar de una parte del patrimonio científico que custodia el CSIC.

Y así gracias a diversas ayudas se está intentando hacer visible con el uso de las nuevas tecnologías de la información y la comunicación los móviles inmutables generados por la Comisión Científica del Pacífico. En primer lugar se informatizó el archivo de Jiménez de la Espada, y se digitalizó su fondo iconográfico. Posteriormente se editó un CD-Rom, en el que se presenta a su usuario de una manera atractiva todo el album de fotografías relacionadas con la expedición del Pacífico que custodia el CSIC, y que hará posible futuros estudios sobre cómo representó la naturaleza y las culturas americanas el dibujante-fotógrafo de esa expedición (Molina et al., 2000). Y en la actualidad se ha construido y se va a seguir desarrollando un sitio en Internet - www.pacifico.csic.es - en el que se intenta ofrecer un sistema de información multidocumental de las colecciones documentales y científicas de esa expedición que se encuentran en los archivos, bibliotecas y museos del CSIC, y se procura presentar de una manera atractiva algunos de los hitos de aquella expedición, en un proceso paralelo al de otras iniciativas de historiadores de la ciencia que están apostando por hacer una historia digital (Abbott, 2001), al insertar la memoria de la ciencia en Telépolis (41).

De esta manera gracias a las posibilidades que ofrece Internet, la red de redes, las inscripciones acumuladas por los expedicionarios de la Comisión Científica del Pacífico hace casi siglo y medio siguen interpelándonos, y siguen circulando aún entre nosotros, tras muchos desplazamientos por el tiempo y el espacio. De hecho recientemente un periodista brasileño informaba a sus lectores que había encontrado en la Biblioteca Nacional de Río de Janeiro el album con 53 fotografías que los comisionados españoles regalaron al emperador D. Pedro II en 1862 (Seligman, 1999: 62-63), hallazgo que pudo hacer al haber leido en Internet un artículo de otra periodista española en el que se presentó al gran público el hallazgo del mencionado "tesoro oculto de Jiménez de la Espada" (Aznárez, 1999).

\section{CONCLUSIONES}

Siguiendo las idas y vueltas por el espacio y el tiempo de los expedicionarios de la Comisión Científica del Pacífico y de algunas de las miles de muestras que recogieron en su accidentada campaña científica se pueden comprobar dos hechos relacionados con el funcionamiento de la actividad científica "procesionaria" que desencadenó esa expedición.

(41) En la introdcción de Dierig et al. (2000) se ofrece una relación de algunas de esas iniciativas. A ellas habría que añadir otras dos sobre sendas expediciones científicas: una australiana dirigida por Burke y Wills entre 1860 y 1861 cuya historia digital ha sido promovida por la State Library of Victoria en la dirección www.burkeandwills.net/expedition/index.html; y otra norteamericana al Congo, promovida por The American Museum of Natural History entre mayo de 1909 y noviembre de 1915 y cuya magnífica reconstrucción se puede visitar en http://diglib1.amnh.org 
En primer lugar que las inscripciones procedentes del laboratorio americano generadas por esos expedicionarios, así como las interpretaciones que se hicieron sobre ellas, se han ido adquiriendo y construyendo progresivamente. En el transcurso de ese proceso el laboratorio central - en este caso el Museo de Ciencias Naturales de Madrid - no impuso su propia interpretación sobre los objetos capturados por los viajeros que actuaron a tan larga distancia. En un principio desde el nudo de la red se quiso determinar que la expedición debía estar al servicio de un programa de aclimatización, pero después algunas de las colecciones fueron estudiadas atendiendo a otros criterios y preocupaciones científicas. Algunas de esas miles de muestras fueron entonces objeto de investigaciones que siguieron líneas de trabajo variadas: taxonómicas como las llevadas a cabo por el herpetólogo Jiménez de la Espada, y el malacólogo González Hidalgo; fisiológicas como la emprendida por el propio Espada sobre la reproducción del Rhinoderma Darwinii; o biogeográficas como las efectuadas por los zooólogos Cabrera y Haas.

Además los objetos recogidos a distancia alteraron las interpretaciones que desde el centro de la red se hacía del mundo de ahí fuera. Si esa comisión científica fue diseñada como un acto de apropiación de la naturaleza americana, dado el contexto imperialista en el que emergió, no obstante Jiménez de la Espada, tras su experiencia americana, se interesó por ampliar su comprensión de aquellos lugares y gentes, generando una especie de "ciencia federativa". Su "viaje iniciático" le impulsó a emprender un programa de trabajo destinado a dar cuenta del conocimiento científico que se había generado en América en tiempos pretéritos tanto en la época precolombina, como en la era moderna. Sus aportes historiográficos fueron reconocidos, por ejemplo, por sus lectores peruanos como suyos, esclarecedores de su propia experiencia histórica.

En segundo lugar las peripecias de las colecciones científicas, iconográficas y documentales generadas por la Comisión Científica del Pacífico permiten conocer mejor el papel fundamental que cumplen los portavoces de la ciencia procesionaria en el despliegue de las redes que entran y salen de los laboratorios, rol que se acrecienta en aquellas sociedades como la española donde las redes tienden a debilitarse por la discontinuidad de sus esfuerzos científicos, dada su posición semi-periférica en la ciencia-mundo. Ha sido la actuación de esos portavoces la que ha mantenido viva la atención sobre esa expedición en sectores de la opinión pública, y en ciertos investigadores, a lo largo del tiempo, aunque fuese con altibajos.

Durante el último tercio del siglo XIX fue el peculiar programa de investigaciones de Espada el que facilitó el mantenimiento de las redes generadas por la Comisión Científica del Pacífico. Así fue reconocido por los organizadores de un homenaje que se le hizo post-mortem, en el que participaron no sólo los principales representantes de la elite científica española de la época, sino los miembros más representativos de la Institución Libre de Enseñanza, una asociación laica de liberales progresistas, muy comprometida con la modernización educativa y científica española, y una amplia representación de la Sociedad Geográfica de Lima.

Luego en el primer tercio del siglo XX se concatenaron los trabajos de científicos como los zoólogos Cabrera y Haas, el antropólogo Hoyos y Sainz, y el botánico 
Cuatrecasas, y de historiadores de la ciencia como Barreiro, para hacer de portavoces de los logros obtenidos por la Comisión Científica del Pacífico.

En la era de Franco la principal manifestación de interés por esa expedición procedió de Estados Unidos desde donde se hizo en la década de 1960 una exhaustiva reconstrucción de las peripecias del periplo de aquellos viajeros naturalistas por parte del profesor Miller - incitado por la lectura de un texto de Rafael Altamira (42) - , gran historiador liberal y admirador de la obra americanista de Jiménez de la Espada.

En el último cuarto del siglo XX resurgió el interés por aquella aventura científica. Esa atención se acrecentó recientemente gracias en cierta medida a la política emprendida en los últimos tiempos por los archivos, bibliotecas y museos del CSIC para hacer accesible el patrimonio científico que custodian usando las nuevas nuevas tecnologías de la información y comunicación. La participación de esos "lugares de la memoria" en la construcción del Servidor de información world wide web de las colecciones documentales y científicas de la Comisión Científica del Pacífico está permitiendo construir en torno a ese sitio una especie de plaza donde se unen información e investigación, cultura y ciencia, y sentando las bases para que se construya un nudo de una nueva red de interesados por esa singular empresa científica del siglo XIX. Esa aspiración es factible al contar con la colaboración de la Unidad de Coordinación de Bibliotecas del CSIC para su construcción, pues no se ha de olvidar - como sostiene Latour (Latour, Hermant 1996) (43) - que las bibliotecas actúan como nudos de vastas redes donde circulan materias que se han transformado en signos. Si esto fuera así la actividad procesionaria de la Comisión Científica del Pacífico seguirá prolongándose en el tiempo gracias a la acción de nuevos portavoces, estimulando la colaboración entre investigadores europeos y latinoamericanos a través de redes trasatlánticas de comunicación científica, que sostendrían la actividad de una ciencia federativa en el ámbito cultural euro-latinoamericano.

\section{Referencias citadas}

ABBOTT, A., 2001 - Digital history. Nature, 409: 556-557.

ACOSTA RIZO, C., CUVI, N. \& ROQUÉ, X., 2003 - Ciencia entre España e Hispanoamérica. Ecos del siglo XX,135p.; Barcelona: Centre d'Estudis d'Història de les Ciències. Universitat Autónoma de Barcelona, Fundación Española de Ciencia y Tecnología, Ministerio de Ciencia y Tecnología.

ALMAGRO, M., 1984[1866] - La Comisión Científica del Pacífico. Viaje por Sudamérica y recorrido del Amazonas 1862-1866, 174p.; Barcelona: Laertes. Estudio preliminar de Lily Litvak.

(42) Según comunicación personal del profesor Miller de 26 de julio 2000 la obra de Altamira que le llevó a interesarse por la Comisión Científica del Pacífico fue su libro The Share of Spain in the History of the Pacific Ocean, New York, Macmillan, 1917.

(43) Se puede consultar en la pagina de Internet http://www.ensmp.fr/ latour/Articles/ 64 bibliotheque.html 
ARAGÓN, S., 2002 - Le rayonnement international de la Société Zoologique d'Acclimatation : participation de l'Espagne entre 1854 et 1861, París: École des Hautes Études en Sciences Sociales, Mémoire de DEA “Histoire et Civilisations", sous la direction de Jean-Marc Drouin, 100p. + XLIII.

AMOR, F., 1856 - Estudios que sobre la Agricultura en sus varias aplicaciones ha hecho en la Exposición Universal de Paris el doctor D. Fernando Amor, 243p.; Córdoba.

AMOR, F., 1859 - Recuerdos de un viaje a Marruecos; Sevilla.

AZNÁREZ, M., 1999 - El tesoro oculto de Jiménez de la Espada. El País Semanal, domingo 14 de marzo: 30-49.

BADIA, S., PÉREZ-MONTES, C. M. \& LÓPEZ-OCÓN, L., 2000 - Una galería iconográfica. In: Marcos Jiménez de la Espada (1831-1898). Tras la senda de un explorador (L. López-Ocón \& C. M. Pérez-Montes, eds.): 121-154; Madrid: CSIC.

BARREIRO, A. J., 1926 - Historia de la Comisión Científica del Pacífico (1862 a 1865), 525p.; Madrid: Museo Nacional de Ciencias Naturales.

BARREIRO, A. J., 1928 - Diario de la expedición al Pacífico llevada a cabo por una comisión de Naturalistas españoles durante los años 1862-1866, escrito por Marcos Jiménez de la Espada, miembro que fue de la misma. Publícalo por vez primera, adicionado con notas, el P. Agustín Jesús Barreiro, agustino, 257p.; Madrid: Real Sociedad Geográfica.

BLANCO FERNÁNDEZ DE CALEYA, P., 1998 - Los herbarios de Mutis e Isern. Asclepio, 40(1): 359-373.

BLANCO FERNÁNDEZ DE CALEYA, P. \& PUIG-SAMPER, M. A., 1995 - Plantas de R. A. Philippi (1808-1904) en el herbario de la Comisión Científica al Pacífico (1862-1866) del Real Jardín Botánico de Madrid. Anales Jardín Botánico de Madrid, 53(1): 55-99.

BLANCO FERNÁNDEZ DE CALEYA, P. \& RODRÍGUEZ VEIGA, M. D., 1996 - Comisión Científica del Pacífico (1862-1866). Estado actual del herbario Isern en el Real Jardín Botánico de Madrid. Revista Sociedad Española de Historia Natural. Tomo extraordinario: $480-483$

BECK, H., 1971 - Alexander von Humboldt, 491p.; México: FCE.

BENAZUNA, 1859 - Noticias sobre la historia de la fotografía. La América, vol. III, nº 15.

BUSTAMANTE, J., 2000 - El historiador. In: Marcos Jiménez de la Espada (1831-1898). Tras la senda de un explorador (L. López-Ocón \& C. M. Pérez-Montes, eds.): 91-94; Madrid: CSIC.

CABRERA LATORRE, A., 1900 - Estudios sobre una colección de monos americanos. Anales de la Sociedad Española de Historia Natural, Serie Zoología, n 29: 65-93, 1 lámina.

CABRERA LATORRE,A., 1901a - Descripción de tres nuevos mamíferos americanos. Boletín de la Sociedad Española de Historia Natural, vol. I: 367-373.

CABRERA LATORRE, A., 1901b - Nota sobre la iconografía del Vespertilio Espadae. Cabr. Boletín de la Sociedad Española de Historia Natural, vol. II: 131-132.

CABRERA LATORRE,A., 1901c - Nota sobre el verdadero hábitat del Myotis Thomesi. Boletín de la Sociedad Española de Historia Natural, vol. II: 293.

CABRERA LATORRE, A., 1904 - Catálogo descriptivo de los Quirópteros chilenos. Revista Chilena de Historia Natural, 7: 278-308.

CABRERA LATORRE, A., 1907 - A new South American Bat. In: Proceedings of the Biology Society of Washington, vol. XXII: 57-58.

CABRERA LATORRE, A., 1913 - Dos mamíferos nuevos de la fauna neotropical. Trabajos del Museo Nacional de Ciencias Naturales. Serie zoológica, $\mathbf{n}^{\mathbf{0}}$ 9: 16p.

CABRERA LATORRE, A., 1917 - Mamíferos del viaje al Pacífico, verificado de 1862 a 1865 por una comisión de naturalistas enviada por el gobierno español. Trabajos del Museo Nacional de Ciencias Naturales. Serie zoológica, $\mathbf{n}^{\mathbf{0}}$ 31: 62p. 
CALATAYUD, M. de los A., 1984 - Catálogo de las expediciones y viajes científicos españoles en los siglos XVIII y XIX, 433p.; Madrid: CSIC.

CALATAYUd, M. de los A. \& PUIG-SAMPER, M. A. (eds.), 1992 - Pacífico inédito. Exposición fotográfica, 163p.; Madrid: Lunwerg editores, Museo Nacional de Ciencias Naturales, Madrid Capital Europea de la Cultura, Sociedad Estatal Quinto Centenario.

CALVO, M., 1994 - Informe sobre el material malacológico recogido durante la expedición al Pacífico (1862-1865). In: Diario de Don Francisco de Paula Martínez y Sáez, miembro de la Comisión Científica del Pacífico, 1862-1865: 283-287; Madrid: CSIC. Edición de $\mathrm{M}^{\mathrm{a}}$ de los Angeles Calatayud.

CALLON, M.(dir.), 1988 - La science et ses réseaux. Genése et circulation des faits scientifiques, 214p.; París: Éditons La Découverte, Conseil de l'Europe, Unesco.

CUATRECASAS, J., 1935 - Plantae Isernianae, I. Anales de la Universidad de Madrid (Ciencias), Tomo IV, Fascículo 2: 206-265.

DE LA RIVA, I., 2000 - La obra herpetológica de Jiménez de la Espada: su relevancia y validez después de un siglo. In: Marcos Jiménez de la Espada (1831-1898). Tras la senda de un explorador (L. López-Ocón \& C. M. Pérez-Montes, eds.): 76-90; Madrid: CSIC.

DEL PINO, F., 2000 - El peruanista. In: Marcos Jiménez de la Espada (1831-1898). Tras la senda de un explorador (L. López-Ocón \& C. M. Pérez-Montes eds.): 95-98; Madrid: CSIC.

DIERIG, S., KÄNTEL, J. \& SCHMIDGEN, H., 2000 - The Virtual Laboratoy for Physiology. A Project in Digitalising the History of Experimentalisation of Nineteenth-Century Life Sciences, 43p.; Max-Planck-Institut für Wissenschaftsgeschichte. Preprint 140.

DOMINGO Y SOLER,A., 1866 - Impresiones. En la Exposición de objetos del Pacífico. Album de las familias, $\mathbf{n}^{0}$ 36: 278-279; Madrid 29 de mayo.

DURAN DE LA RUA, N., 1979 - La Unión Liberal y la modernización de la España isabelina. Una convivencia frustrada, 1854-1868, 364p.; Madrid: Akal.

ELENA,A.\& ORDOÑEZ, J., 2000 - Science, Technology and the Spanish Colonial Experience in the Nineteenth Century. Osiris, vol. 15: 70-82.

FAN, F., 2000 - Hybrid Discourse and Textual Practice: Sinology and Natural History in the Nineteenth Century. History of Science, 38: 25-56.

FERNÁNDEZ PÉREZ, J. \& GONZÁLEZTASCÓN, I., 1990 - La agricultura viajera: cultivos y manufacturas de plantas industriales y alimentarias en España y en la América virreinal; Madrid: Lunwerg.

FONTANELLA, L., 1999 - Clifford en España: un fotógrafo en la corte de Isabel II, 335p.; Madrid: El Viso.

GARCÍA-PEREA, R. \& GISBERT, J., 1998 - Angel Cabrera y su contribución a la Mastozoología. In: Fauna Ibérica. Mamíferos: 17-49; Xunta de Galicia \& Universidade de Santiago de Compostela.

GAY, C., 1848 - Historia física y política de Chile. Zoología, Vol. II.; París.

GONZÁLEZ HIDALGO, J., 1872 - Univalvos terrestres. In: Moluscos del viaje al Pacífico verificado de 1862 a 1865 por una comisión de naturalistas enviada por el gobierno español, 1869-1879 (Parte primera); Madrid: Imp. de Miguel Ginesta. Con láminas que contienen 89 figuras.

GONZÁLEZ HIDALGO, J., 1879 - Univalvos marinos. In: Moluscos del viaje al Pacífico verificado de 1862 a 1865 por una comisión de naturalistas enviada por el gobierno español, 1869-1879 (Parte tercera); Madrid: Imp. de Miguel Ginesta.

HAAS, F., 1916 - Náyades del viaje al Pacífico verificado de 1862 a 1865 por una comisión de naturalistas enviada por el Gobierno español, 63p., 2 h. de lám; Madrid: Junta para Ampliación de Estudios e Investigaciones Científicas. Instituto Nacional de Ciencias Físico-Naturales. En castellano y alemán. 
HOYOS Y SAINZ, L. de, 1910 - Cráneos americanos del Museo Antropológico de Madrid. In: Actas del Congreso de Valencia de la Asociación Española para el Progreso de las Ciencias de 1910: 10p.

HOYOS Y SAINZ, L. de, 1911a - Cráneo foguino del Museo Antropológico Nacional. Revista de la Real Academia de Ciencias Exactas, Físicas y Naturales, 11p.; Madrid.

HOYOS Y SAINZ, L. de, 1911b - Cráneos araucanos del Museo Antropológico Nacional. Revista de la Real Academia de Ciencias Exactas, Físicas y Naturales: 10 p.; Madrid.

HOYOS Y SAINZ, L. de, 1913 - Crânes fuéguiens et araucans du Musée Antrhropologique de Madrid. Journal de la Société des Américanistes de Paris, vol. X: 181-194

HOYOS Y SAINZ, L. de, 1923-1924a - Cráneos normales y deformados de los Andes. Tres memorias diferentes. In: Actas y Memorias de la Sociedad Española de Antropología, Etnografía y Prehistoria, vol. II: 151-184.

HOYOS Y SAINZ, L. de, 1923-1924b - Cráneos normales y deformados de los Andes. Tres memorias diferentes. In: Actas y Memorias de la Sociedad Española de Antropología, Etnografía y Prehistoria, vol. III: 3-37 y 185-230.

IGLESIAS, F., 1931 - Anteproyecto de un viaje de exploración por el alto Amazonas estudiado y redactado por el capitán Iglesias y sus colaboradores; Madrid.

JIMÉNEZ DE LA ESPADA, M., 1870 - Faunae neotropicalis, species quaedam nondum cognitae. Jornal de Sciencias Mathematicas, Physicas e Naturaes, tomo III, $\mathbf{n}^{\mathbf{0}}$ IX: 57-65.

JIMÉNEZ DE LA ESPADA, M., 1978[1875] - Vertebrados del viaje al Pacífico. Batracios; Society for the Study of Amphibians and Reptiles.

LAFUENTE, A. \& LÓPEZ-OCÓN, L., 1997 - Le transfert des pratiques scientifiques et techniques dans le contexte de la science-monde. In: Naissance d'une communauté internationale d'ingénieurs (première moitié du XIXème siècle (I. Gouzevitch \& P. Bret, eds.): 6-19; París: Centre de recherche en histoire des sciences et des techniques. Cité des Sciences et de l'Industrie. Actes des journées d'études 15-16 décembre 1994.

LATOUR, B., 1986 - Visualization and Cognition: Thinking with Eyes and Hands. Knowledge and Society, 6: 1-40.

LATOUR, B., 1992 - Ciencia en acción: cómo conseguir a los científicos e ingenieros a través de la sociedad, 278p.; Barcelona: Labor.

LATOUR, B. \& POLANCO, X., 1990 - À propos de l'histoire sociale des sciences : quelques remarques, le modèle de la rosace. In: Naissance et développement de la science-monde. Production et reproduction des communautés scientifiques en Europe et en Amérique latine (X. Polanco, dir.): 53-66; París: Éditions La Découverte, Conseil de l’Europe, Unesco.

LATOUR, B. \& HERMANT, É., 1996 - Ces réseaux que la raison ignore : laboratoires, bibliothèques, collections. In: Le pouvoir des bibliothèques. La mémoire des livres dans la culture occidentale (C. Jacob \& M. Baratin, dirs.): 23-46; París: Albin Michel.

LAW, J. \& HASSARD, J. (ed.), 1999 - Actor Network Theory and After, 256p.; Malden (Ma): Blackwell publ.

LÓPEZ GÓMEZ, P., 2002 - La expedición Iglesias al Amazonas; Madrid: Ministerio de Medio Ambiente. Organismo Autómono de Parques Nacionales.

LÓPEZ PIÑERO, J. M., 1979 - Ciencia y técnica en la sociedad española de los siglos XVI y XVII, 511p.; Barcelona: Editorial Labor.

LÓPEZ-OCÓN, L., 1987 - Biografía de "La América". Una crónica hispano-americana del liberalismo democrático español (1857-1886), 215p.; Madrid: CSIC.

LÓPEZ-OCÓN, L., 1991 - De viajero naturalista a historiador: Las actividades americanistas del científico español Marcos Jiménez de la Espada (1831-1898), Tesis doctoral, Universidad Complutense de Madrid, 2 vols., 1366p.

LÓPEZ-OCÓN, L., 1992 - Ciencia e historia de la ciencia en el Sexenio democrático. La formación de una tercera vía en la polémica de la ciencia española. Dynamis, vol. 12: 87-103; Universidad de Granada. 
LÓPEZ-OCÓN, L., 1995 - La Comisión Científica del Pacífico (1862-1866) y la Commission Scientifique du Mexique (1864-1867): paralelismos y divergencias de dos proyecciones latinoamericanas de la ciencia europea. In: De la ciencia ilustrada a la ciencia romántica (A. R. Díez Torre et al., coords.): 459-475; Aranjuez: Doce Calles, Ateneo de Madrid.

LÓPEZ-OCÓN, L., 1997 - El fomento de la educación y de la ciencia en la sociedad española del sexenio democrático. Boletín Institución Libre de Enseñanza, $\mathbf{n}^{\mathbf{0}}$ 28-29: 127-148.

LÓPEZ-OCÓN, L., 1998 - La exhibición del poder de la ciencia. La América Latina en el escenario de las exposiciones universales del siglo XIX. In: O Mundo Ibero-Americano nas Grandes Exposições (J. A. Mourão, A. M. Cardoso de Matos \& M. E. Guedes, coords.): 67-89; Lisboa: Vega.

LÓPEZ-OCÓN, L., 1999 - Un naturalista en el panteón. El culto a Humboldt en el Viejo y el Nuevo Mundo. Cuadernos Hispanoamericanos, 586: 21-34.

LÓPEZ-OCÓN, L., 2000a - The circulation of the work of Hernández in Nineteen-Century Spain. In: Searching for the secrets of nature: the life and works of Dr. Francisco Hernández (S. Varey, R. Chabrán \& D. B. Weiner, eds.): 183-193; Stanford: Stanford University Press.

LÓPEZ-OCÓN, L., 2000b - Génesis y desarrollo del programa editorial peruanista de Jiménez de la Espada: sus acercamientos al cronista Fernando de Montesinos entre 1868 y 1882. In: Edición e interpretación de textos andinos (I. Arellano \& J. A. Mazzotti, eds.): 87101; Universidad de Navarra, Iberoamericana, Vervuert.

LÓPEZ-OCÓN, L., 2000c - Los significados de un homenaje: ayer y hoy. In: Marcos Jiménez de la Espada (1831-1898). Tras la senda de un explorador (L. López-Ocón \& C. M. Pérez-Montes, eds.): 59-68; Madrid: CSIC.

LÓPEZ-OCÓN, L., 2002 - El papel de los primeros congresos internacionales de americanistas en la construcción de una comunidad científica. In: Elites intelectuales y modelos colectivos. Mundo ibérico (siglos XVI-XIX) (M. Quijada \& J. Bustamante, eds.): 271284; Madrid, CSIC.

LÓPEZ-OCÓN, L., 2003 - Breve historia de la ciencia española, 479p.; Madrid: Alianza Editorial.

LÓPEZ-OCÓN, L. \& PUIG-SAMPER, M. A., 1988 - Los condicionamientos políticos de la Comisión Científica del Pacífico: Nacionalismo e Hispanoamericanismo en la España bajoisabelina (1854-1868). In: Estudios sobre historia de la ciencia y de la técnica, vol. II (M. E. Piñero et al., coords.): 615-629; Valladolid: Junta de Castilla y León.

LÓPEZ-OCÓN, L. \& GARCÍA-MONTÓN, M. I., 2000 - La Habana: un núcleo y portal de ciencia (1857-1867). In: La Habana. Puerto colonial, siglos XVIII-XIX (A. Guimerá \& F. Monge, coords.): 283-307; Madrid: Fundación Portuaria.

LÓPEZ-OCÓN, L. \& PÉREZ-MONTES, C. M., 2000 - Marcos Jiménez de la Espada (18311898). Tras la senda de un explorador, 384p.; Madrid: CSIC.

MACKENZIE, J. M. (ed.), 1990 - Imperialism and the natural world, 216p.; Manchester; New York: Manchester University Press.

MARTÍNEZ Y SAÉNZ, F. de P., 1869 - Bivalvos marinos. In: Moluscos del viaje al Pacífico verificado de 1862 a 1865 por una comisión de naturalistas enviada por el gobierno español, 1869-1879 (Segunda parte); Madrid: Imp. de Miguel Ginesta.

MILLER, R. R., 1983 - Por la Ciencia y la Gloria Nacional. La expedición científica española a América (1862-1866), 256p.: Barcelona: ediciones del Serbal.

MOLINA, J., PÉREZ-MONTES, C. \& LÓPEZ-OCÓN, L., 2000 - Catálogo de fotografías de la Comisión Científica del Pacífico. Colección CSIC, CD-ROM; Madrid: CSIC.

MURRA, J. V., 1978 - La organización económica del estado inca, 270 p.; México: Siglo XXI.

MURRA, J. V., 1984 - Andean societies before 1532. In: Colonial Latin America, vol. I The Cambridge History of Latin America (L. Bethell, ed.): 59-90; Cambridge University Press. 
OSBORNE, M. A., 1994 - Nature, the Exotic, and the Science of French Colonialism: science, technology and society, 216p.; Bloomington (Ind): Indiana university press.

OSBORNE, M. A., 2000 - Acclimatizing the World: A History of the Paradigmatic Colonial Science. Osiris, vol. 15: 135-151.

PÁEZ RÍOS, E., 1952 - Índices del Museo Universal. Madrid (1857-1869); Madrid: CSIC.

PALMQUIST, P. E,. 1982 - Don Rafael's Tree. History of Photography, 6(1): 15- 19.

POLANCO, X., 1990 - Une science-monde : la mondialisation de la science européenne et la création de traditions scientifiques locales. In: Naissance et développement de la sciencemonde. Production et reproduction des communautés scientifiques en Europe et en Amérique latine (X. Polanco, dir.): 10-52; París: Éditions La Découverte, Conseil de l'Europe, Unesco.

PUIG-SAMPER, M.A., 1986 - La organización de la expedición al Pacífico en 1862. Un proyecto político-científico para articular el sistema colonial español. Quipu, 3(3): 335-348.

PUIG-SAMPER, M. A., 1988 - Crónica de una expedición romántica al Nuevo Mundo, 459p.; Madrid: CSIC.

RYAN, J.R., 1997 - Picturing Empire: Photography and the Visualization of the British Empire, 272p.; London: Reaktion Books.

SANTOS MAZORRA, C. M., 1994 - Catálogo de los insectos recolectados por la Comisión Científica del Pacífico (1862-1865), 196p; Madrid: Museo Nacional de Ciencias Naturales. CSIC.

SAVAGE, J. M., 1978 - Marcos Jiménez de la Espada, naturalist explorer of the Andes and upper Amazon basin. Introduction. In: Marcos Jiménez de la Espada, Vertebrados del viaje al Pacífico. Batracios: VII-XVI; Society for the Study of Amphibians and Reptiles.

SELIGMAN, A., 1999 - Epopéia tropical. A saga dos espanhóis que cruzaram o Brasil há 140 anos e as fotos, agora descobertas. Veja, 23 de junho de 1999.

SOBERANIS, A., 1998 - La expansión geográfica de la ciencia. Orígenes históricos de la Commission Scientifique du Mexique. Revista del Seminario de Historia Mexicana, 1(3): 9-75.

SOUGEZ, M.-L., 1994 - Historia de la fotografía, 518p.; Madrid: Cátedra.

SPARY, E. C., 2000 - Utopia's Garden. French natural history from old regime to revolution, 321p.; Chicago: University of Chicago Press.

SPENGEL, J.W., 1872 - Mit einigen einleitenden Bemerkungen. Zeitschrift für Wissenschaftliche Zoologie, 29: 495-501.

SPENGEL, J. W., 1877 - Die Fortpflanzung des Rhinoderma Darwinii. Nach dem Spanischen des Jimenez de la Espada. Anales de la Sociedad Española de Historia Natural, tomo I: 139.

TORTELLA, G., 1975 - Los orígenes del capitalismo en España.Banca, industria y ferrocarriles en el siglo XIX, 407p.; Madrid: Tecnos.

TREFFER, G. (ed.), 1973 - Die Weltumseglung der "Novara” 1857-1869. [Von] Karl von Scherzer, 224p.; Wien, München, Zürich: Molden.

VAN AKEN, M. J., 1959 - Pan-hispanism. Its Origin and Development to 1866, 166p.; Berkeley: University of California Press.

VIEJO MONTESINOS, J. L., 1992 - Biografía de un naturalista y biología del lepidóptero por él descrito. Graells y la Graellsia. Quercus, 74: 22-29.

VISCHER, E., 1864 - Sequoia Gigantea, Calaveras Mammoth Tree Grove, 1 leaf, [4] p., 12 leaves of plates; San Francisco: E. Vischer.

VISCHER, E., 1870 - Vischer's pictorial of California, landscape, trees and forest scenes: grand features of California scenery, life, traffic and customs: photographs from the original drawings, in five series of twelve numbers each, with a supplement, and contributions from reliable sources, 5 hojas, 132, iii p + atlas de 169 fotos; San Francisco: J. Winterburn. 